\title{
El límite sur de la necrópolis medieval judía del Cerro de la Horca (Toledo) y el problema del contacto con otros cementerios
}

Arturo Ruiz Taboada*

Centro de Estudios Internacionales, Fundación Ortega Marañón

La excavación de un solar localizado en el número 25 de la calle General Villalba ha permitido identificar lo que pudo configurar parte del límite sur del cementerio judío medieval del Cerro de la Horca, en una zona caracterizada por la convergencia de cementerios de diferentes religiones: el ya mencionado judío, un segundo musulmán de época Taifa asociado al camino de Madrid y un tercero cristiano, dependiente de la ermita de San Eugenio. Además, la ausencia de lucillos y la presencia de tumbas en covacha lateral y escalonadas vienen a completar tanto la tipología de enterramientos conocida para este cementerio como su evolución y desarrollo.

Palabras Clave: Expansión; límites; agua; cementerio; judío; musulmán.

The Southern Bound of the Medieval Jewish Cemetery of the Cerro de la Horca (Toledo): The Other Cemeteries Contact Problem.- The archaeological excavation of a plot on 25 General Villalba St. has allowed for the identification of what could have been part the southern end of the Medieval Jewish Cemetery of the Cerro de la Horca, an area characterized by the presence of three different rite cemeteries: the aforementioned Je-wish cemetery, a Muslim Taifa Period cemetery linked to the Madrid road, and a Christian cemetery associated to the San Eugenio hermitage. In addition, the lack of lucillos (brick half-barrelled vaults) and the presence of side covacha (rock-cut) and terraced tombs contributes to a more complete knowledge of both the burial typology known for this cemetery, and its evolution and development.

KEYwords: Location; Expansion; Boundaries; Water; Cemetery; Jewish; Muslim.

\footnotetext{
*31416art@gmail.com
} 


\section{INTRODUCCIÓN}

La identificación de los límites arqueológicos de los cementerios medievales no siempre es sencilla, debido a que en muchas ocasiones carecían de cierres físicos y se han visto afectados por el cambio de uso del espacio y las sucesivas transformaciones a lo largo de los siglos. A esto hay que sumar el enorme desarrollo de los núcleos urbanos, lo que ha originado que muchos de ellos se localicen bajo el ensanche de las ciudades.

Toledo puede servir de laboratorio para analizar la viabilidad de muchas de las interpretaciones arqueológicas formuladas para conocer el mundo funerario medieval y, en concreto, judío peninsular. Este artículo pretende mostrar la complejidad de argumentar arqueológicamente cuestiones tan subjetivas como los ritos y costumbres de gentes que hace siglos dejaron de existir, no así su tradición religiosa, asumiendo que no siempre se acierta al tratar de extrapolar nuestra realidad al pasado' . Así, la existencia de una ingente dispersión de tumbas de diferentes épocas por toda la llanura norte de Toledo ha dificultado el estudio e individualización de los múltiples patrones de enterramiento históricos practicados por la sociedad toledana. En los últimos años hemos asistido a intentos de sistematizar este tipo de yacimientos con más o menos éxito. Rodríguez Fernández y Rosado Tejerizo $^{2}$ recientemente han extractado las dos teorías que han condicionado en las últimas décadas la investigación cementerial de esta zona: por un lado, aquella que defiende la existencia de varios cementerios en la llanura norte de Toledo: cristianos en la iglesia de Santa Leocadia de Afuera, judíos en el Cerro de la Horca y musulmanes en el circo romano, bien diferenciados entre sî́. Por otro, las tesis de Clara Delgado que concebía la existencia

\footnotetext{
${ }^{1}$ Agradezco a los tres evaluadores ciegos las sugerencias hechas al borrador de este artículo.

${ }^{2}$ A. Rodríguez Fernández y E. Rosado Tejerizo, «Excavación arqueológica en la necrópolis medieval de San Lázaro, Toledo», en Arqueologia de Transição: O Mundo Funerário. Actas do II Congresso Internacional Sobre Arqueologia de Transição (29 de Abril a 1 de Maio 2013), eds. G. Branco, L. Rocha, C. Duarte, J. de Oliveira y P. Bueno RAMírez (2015) págs. 224-233: 225.

${ }^{3}$ A. DE JuAn, Los enterramientos musulmanes del circo romano de Toledo (= Museo de Santa Cruz. Monografías 2 [Toledo 1987]); «Los cementerios islámicos de Toledo en la Edad Media», en Actas digitales del Congreso La Muerte en el Tiempo (Talavera de la Reina 2011) págs. 265-291; L. ToRres BALBÁs, «Cementerios hispanomusumanes»,
} 
de un espacio cementerial relacionado con una de las puertas de la ciudad (Antigua de Bisagra) sobre una amplia extensión de terreno, en donde confluirían la necrópolis romana y visigoda, junto con la musulmana, judía y cristiana ${ }^{4}$. Una extensa alfombra de tumbas sin solución de continuidad, configurando una vasta ciudad de los muertos.

La teoría de Delgado sin duda es la más atractiva, sobre todo por considerar los cementerios históricos como lugares de encuentro, en donde huertas y caminos convivirían con las tumbas. No obstante, la evidencia arqueológica apunta más a una atomización de estos espacios, obligando a asumir, como así lo recogieron las fuentes históricas -con todas las reservas que conlleva su lectura-, que la llanura norte de Toledo contiene un enorme catálogo de cementerios cada uno perfectamente acotado, física o simbólicamente, e individualizado del resto. El verdadero problema con el que se han encontrado los diferentes investigadores ha sido la falta de datos empíricos derivados de excavaciones arqueológicas que ayuden a individualizar todos esos ambientes. Las últimas décadas han conocido un espectacular aumento de excavaciones al amparo de la legislación vigente en materia de Patrimonio Histórico ${ }^{5}$, que ha contribuido a matizar muchas de las hipótesis que se manejaban hasta ese momento. Pese a que las publicaciones científicas no van a la par de la ingente cantidad de restos descubiertos, hoy en día se puede hablar de una clara diferenciación del espacio de enterramiento en el conjunto de la llanura norte, no sólo por la localización de aquellos cementerios romanos y visigodos, musulmanes, cristianos y judíos de los que habla la historiografía, sino también por sus límites, extensión aproximada, cronología, crecimiento y desarrollo interno ${ }^{6}$.

Nadie discute que la llanura norte constituye un inmenso espacio cementerial que ha sido ocupado sin solución de continuidad a lo largo de la historia reciente. Lo que sí se discute es si en ese cementerio las tumbas se distribuyen

Al-Andalus XXII (1957) págs. 131-191; Ciudades hispanomusulmanas (Madrid 1985) pág. 265.

${ }^{4}$ C. Delgado Valero, «El cementerio musulmán de Toledo», en Simposio Toledo hispanoárabe (Toledo 1986) págs. 187-191.

${ }^{5}$ Cf. Ley de Patrimonio de Castilla La Mancha (4/13).

${ }^{6}$ A. Ruiz Taboada, «Comments on Muslim, Jewish and Christian Burial Practices in Medieval Toledo (Spain)», Journal of Islamic Archaeology 2:1 (2015) págs. 51-71. 
de forma ordenada o desordenada, y de qué manera conviven multitud de ritos y tradiciones de enterramiento. No obstante, frente a considerar esta llanura como un espacio desordenado, poco a poco se va imponiendo la idea de un espacio cementerial segmentado. Dicho espacio sería rico en tradiciones culturales, fases de ocupación de las tres religiones mayoritarias, perfectamente ordenadas, definidas e independientes las unas de las otras, con las lógicas intromisiones y contactos producto del paso del tiempo.

Para esta tipificación es necesaria la puesta en práctica de una nueva metodología de trabajo que abogue no sólo por la excavación y documentación arqueológica de los restos, sino por su contextualización en el conjunto de la llanura. Hasta el momento, cada excavación arqueológica es el resultado de la intervención acotada por motivos urbanísticos, para la construcción de nuevas viviendas o similar. Así, el trabajo de campo únicamente se ha centrado en describir lo que aparece en ese micro-entorno, obviando en muchas ocasiones su contexto arqueológico, con todos los problemas que ello conlleva ${ }^{7}$.

Con este planteamiento, la excavación del número 25 de la calle General Villalba aporta nuevos datos para comprender la dinámica del cementerio judío localizado en el Cerro de la Horca y, en concreto, su posible límite sur (fig. 1). Por regla general, los cementerios de este rito siempre buscan lugares alejados de los núcleos urbanos en su idea de que el cuerpo pueda permanecer inviolable en espera de la resurrección ${ }^{8}$. La teoría refiere a que su suelo sólo podía ser dedicado al entierro de judíos y no debía haber sido utilizado previamente con otro fin. En la práctica, conforme contamos con más información arqueológica vemos cómo no siempre se cumplen los preceptos establecidos y, sobre todo, surgen nuevos problemas a la hora de establecer los límites y su relación con otras zonas ocupadas por otras religiones. En nuestro caso, el problema radica en que alguna de las tumbas judías cortan enterramientos anteriores pertenecientes a un cementerio andalusí localizado en las inmediaciones (fig. 1), en una evidente reutilización de un espacio funerario previo.

${ }^{7}$ R. IzQUiERdo BEnIto, «Arqueología de una minoría: La cultura material hispanojudía», en El legado material hispanojudio, eds. A. LóPEz Álvarez y R. IzQUIERDo Benito (Cuenca 1998) págs. 265-292: 282.

${ }^{8}$ J. Casanovas Miró, «Notas sobre arqueología funeraria judía en época medieval», Espacio Tiempo y Forma 6 (1993) págs. 293-302: 293. 


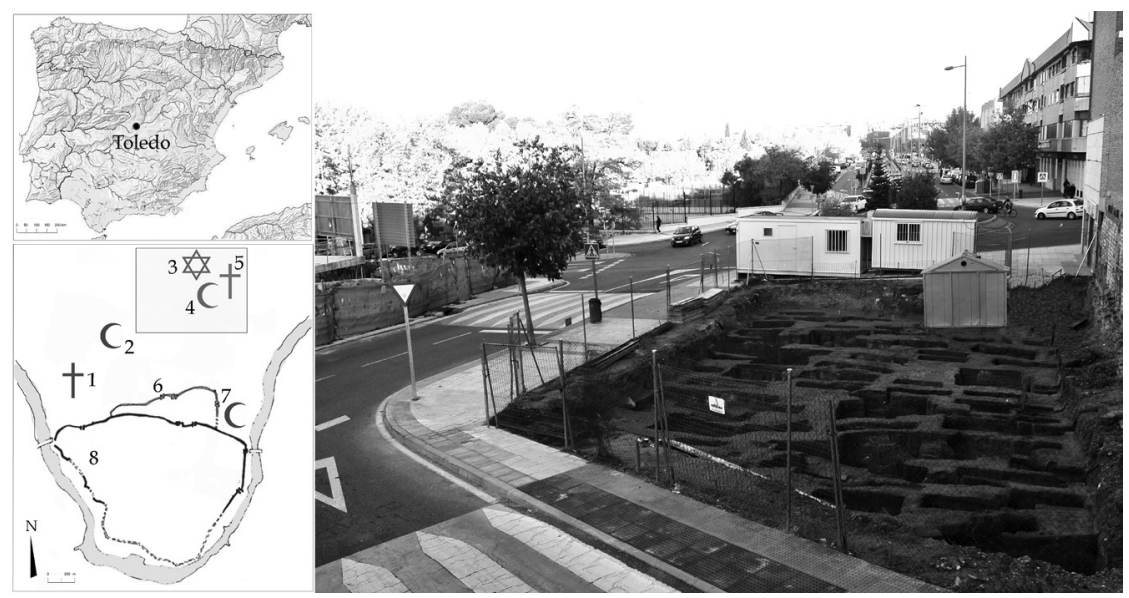

Figura 1: Vista del final de la excavación de General Villalba, núm. 25, desde el sur. Mapa de dispersión de los núcleos de los principales cementerios medievales toledanos: 1. Cementerio de Santa Leocadia de Afuera; 2. Cementerio del Circo Romano; 3. Cementero del Cerro de la Horca (fig. 2); 4. Cementerio del Camino de Madrid; 5. San Eugenio; 6. Puerta Antigua de Bisagra; 7. Cementerio de la Puerta del Vado; 8. Judería.

\section{Metodología}

El proyecto de excavación se hace atendiendo a los criterios anteriormente expuestos y fundamentado en las únicas publicaciones recientes de solares limítrofes como el Quixote Crea (U2 del PERI de San Lázaro) ${ }^{9}$, Valdivias Covarrubias $^{10}$, General Villalba 20, 22, 30 ${ }^{11}$ y el IES Azarquiel ${ }^{12}$

\footnotetext{
${ }^{9}$ Rodríguez Fernández y Rosado Tejerizo, «Excavación arqueológica».

${ }^{10}$ V. Requejo López y R. Maqueda García-Morales, «Excavaciones en el cementerio medieval del Cerro de la Horca: C/ Valdivias - C/ Covarrubias», en Actas de las II Jornadas de Arqueología de Castilla La Mancha, coords. M. Perlines y A. Madrigal ([Toledo] 2010) págs. 726-763.

${ }^{11}$ S. Rodríguez Untoria, «Excavación arqueológica en avenida general Villalba 20, 22 y 34 (Toledo). Aporte al estudio de la necrópolis medieval de Toledo» en Actas de las II Jornadas de Arqueología de Castilla La Mancha, coords. M. Perlines y A. Madrigal ([Toledo] 2010) págs. 2-35.

12 A. Ruiz Taboada, «La necrópolis medieval del Cerro de la Horca», Sefarad 69:1 (2009) págs. 25-41; «La necropole juive de Tolède: Type, construction et distribution des tombes», en L'Archéologie du judaïsme en France et en Europe (Paris 2011) págs. 289-300.
} 
o antiguas, como la del camino del cementerio ${ }^{13}$. La excavación de General Villalba 25 abarca una superficie aproximada de $290 \mathrm{~m}^{2}$. El trabajo de campo ha pretendido responder a cuestiones que tienen que ver con el tipo de tumba, la profundidad a la que aparece y el grado de alteración sufrido desde su fundación hasta nuestros días. Con este fin, únicamente se ha excavado en extensión el nivel superficial en torno a los $40 \mathrm{cms}$ de espesor para localizar las fosas en planta, teniendo en cuenta que la delimitación vertical de las tumbas se ha perdido como consecuencia de la sabida venta de lápidas en época de los Reyes Católicos ${ }^{14}$. Recordemos que esta comercialización de lápidas es un denominador común para todos los cementerios de Sefarad ${ }^{15}$ en los que tenemos multitud de casos documentados, como el uso que se da a estas piedras en Haro para la construcción de un puente, o en Miranda de Ebro ${ }^{16}$ para la reforma del concejo de la ciudad. Aunque no siempre esta amortización del espacio significó su destrucción, Cantera Montenegro menciona la reserva que se plantea en cementerios como Calahorra o Vitoria (Judizmendi), en el que -para este último-, se acuerda su cesión como dehesa concejil a cambio de que el cementerio nunca fuera destinado a labores agrícolas y de que no se construiría sobre él, siendo su uso para el ganado común del concejo ${ }^{17}$.

En el caso del Cerro de la Horca, la ausencia de lápidas in situ impide no sólo certificar definitivamente el cementerio como judío, sino conectar el registro arqueológico con el entorno social del difunto; entorno que sí conocemos tanto por la transcripción de 76 epitafios ${ }^{18}$ que un copista

${ }^{13}$ R. Amador de los Ríos, «Excavaciones en Toledo. Memoria de los resultados obtenidos en las exploraciones y excavaciones practicadas en el año 1916», Memorias de la Junta Superior de Excavaciones y Antigüedades, núm. 3 (Madrid 1917) págs. 6-36.

${ }^{14}$ J. Gómez Menor, «Algunos datos sobre el cementerio judío de Toledo», Sefarad 31:2 (1971) págs. 367-375: 368.

${ }^{15}$ Casanovas Miró, «Notas sobre arqueología funeraria judía», pág. 298.

${ }^{16}$ E. Cantera Montenegro, «Los últimos tiempos de la presencia judía en Calahorra y La Rioja», Kalakorikos: Revista para el estudio, defensa, protección y divulgación del patrimonio histórico, artístico y cultural de Calahorra y su entorno 10 (2005) págs. 5786: 74 y 78 .

${ }^{17}$ Cantera Montenegro, «Los últimos tiempos», pág. 77

${ }^{18}$ Investigaciones como la planteada por Elíshabá Mata López sobre estas lápidas analizan las inscripciones funerarias como una forma de acceder al contexto sociocultural de la comunidad judía. 
anónimo hizo en el siglo XVI ${ }^{19}$, como por algunas lápidas inscritas conservadas tanto en el Museo Sefardí como integradas en monumentos o casas de la ciudad de Toledo. Las únicas inscripciones funerarias halladas en el Cerro de la Horca fueron documentadas por Amador de los Ríos, a inicios del siglo $\mathrm{XX}^{20}$, aunque descontextualizadas y sobre soportes que no se ajustan al diseño trapezoidal de sección piramidal característico del registro típico toledano. Como veremos, la más representativa se encuentra en el reverso de un cipo de época Taifa reutilizado como cierre superficial de una tumba judía (fig. 5, núm. 4). Independientemente de que estas reutilizaciones no son comunes en Sefarad ${ }^{21}$, la pieza ofrece información sobre el contexto social del difunto, puesto que su reciclaje sugiere el bajo nivel adquisitivo de su entorno. Así, debido a la ausencia de ajuares funerarios, únicamente contamos con el diseño arquitectónico de los cierres subterráneos de las tumbas y la factura de las lápidas para establecer la posible relevancia social de sus inquilinos.

Fuera del entorno del Cerro de la Horca existe un tercer tipo de delimitación superficial asociado a enterramientos judíos. En este caso el soporte es ladrillo (fig. 5, núm. 3), y fue descubierto a finales del siglo XIX en la desaparecida venta de la Esquina, supuestamente en el entorno de la antigua Fábrica de Armas, actual Universidad de Castilla La Mancha (paraje conocido como la Vega Baja). La inscripción ha sido analizada entre otros por Jordi Casanovas, que la sitúa entre los siglos IX y XI por paleografía $^{22}$. Con todas las reservas sobre su procedencia, la cronología y el hecho de que el uso de este tipo de soportes sea característico del mundo andalusí toledano, abre la puerta para considerar la existencia de otros enclaves funerarios judíos tanto en la Alta Edad Media como sugiere Casanovas, o en épocas Visigoda y Romana.

Con respecto al suelo bajo lápida, se han dado casos en los que se ha conservado la evidencia material de preparación y nivelación del terreno para su asiento. Su identificación es clave para localizar las fosas. Se han

${ }^{19}$ P. León Tello, «La historia de los judíos toledanos del siglo XIV, en los documentos», Anales Toledanos 18 (1984) págs. 45-62.

${ }^{20}$ Amador de los Ríos, «Excavaciones en Toledo».

${ }^{21}$ J. Casanovas Miró, Epigrafía Hebrea. Real Academia de la Historia. Catálogo del Gabinete de Antigüedades (Madrid 2005) pág. 96.

${ }^{22}$ Casanovas Miró, Epigrafía Hebrea, pág. 97. 
documentado diversos acabados que van desde suelos de espiga de ladri$1 \mathrm{lo}^{23}$, cercos de mampostería ${ }^{24}$ y una amplia variedad de materiales entre pequeños mampuestos, fragmentos de teja o ladrillos. La escasez de la muestra publicada impide, por el momento, relacionar estas preparaciones del terreno con un ritual funerario concreto, siendo las tumbas en su conjunto las que deban definir su filiación cultural.

Tras la identificación superficial de estas fosas, se procede a su excavación en negativo para conocer su profundidad. Esto posibilita la documentación de las diferentes afecciones que pudieran haber sufrido o provocado estas fosas, tomando como referencia el grado de alteración del nivel geológico (en esta zona denominado alcaén y compuesto por areniscas arcósicas, conglomerados y arcillas). La transformación y ruptura de muchas de ellas nos aporta información sobre las distintas fases de ocupación del espacio y, en su caso, permite reconocer fácilmente diferencias en cuanto a rito y tipología. Pese a que su estructura estratigráfica tiende a ser horizontal, cada tumba puede interrelacionarse diacrónicamente con el resto, lo que complica la identificación de una hipotética distribución lineal.

Desde un punto de vista constructivo, las tumbas suelen constar de dos cierres: el ya referido vertical y el subterráneo. La excavación del cierre subterráneo aporta información decisiva sobre la posible adscripción cultural, junto a las técnicas y materiales empleados en la fabricación de la tumba, así como la preparación del asiento para la deposición del cadáver. La colocación nos sirve tanto para contextualizar al individuo en el conjunto del cementerio como diferenciarlo de otras tumbas ajenas al mismo.

Las diferentes religiones van a utilizar sus propios fósiles directores en materia de cierre subterráneo, no obstante, muchas de ellas van a compartir técnicas constructivas similares, lo que complica su interpretación. Por citar un ejemplo, a los judíos de Toledo o Sevilla se les asocia con la bóveda de ladrillo o lucillo como cierre subterráneo, pero ello no impide

\footnotetext{
${ }^{23}$ A. Ruiz TABoAda, La vida futura es para los devotos: la muerte en el Toledo Medieval (Madrid 2013) pág. 72, fig. 80, tumba 2.

${ }^{24}$ Rodríguez FernándeZ y Rosado TeJerizo, «Excavación arqueológica», pág. 231, tumba 127.
} 
que puedan utilizar otras fórmulas de cierre como la madera, las lajas de piedra o la covacha ${ }^{25}$. El ritual musulmán muestra preferencia por tejas, lajas de piedra o tapas de madera ${ }^{26}$, mientras que los cristianos por tapas de madera o lajas de piedra como cierre de sus tumbas antropomorfas ${ }^{27}$.

Con respecto a la colocación del cadáver, ésta nunca puede ser elemento definitorio del ritual, pues como veremos y hemos visto en otros cementerios, puede responder a cuestiones post-deposicionales, de perdida de conexión anatómica u otros factores. La colocación de la cabeza en el mundo judío es buena prueba de ello. En el caso de que no se encuentre calzada y repose sobre el geológico directamente o una almohadilla, podemos encontrar individuos con ella mirando al cielo o caída a derecha o izquierda. La información más representativa proviene del esqueleto en su conjunto. Aunque siempre aplicando las mismas reservas, se puede generalizar que los rituales cristianos y judíos tienden al decúbito supino, mientras que los musulmanes al lateral derecho o semi-decúbito lateral derecho con la cara, esta vez sí, apostada intencionalmente al este.

La orientación de los cuerpos tampoco es concluyente para establecer la caracterización religiosa de los enterramientos, existiendo multitud de condicionantes, algunos de los cuales trataremos en este artículo. En general, se puede hablar de una orientación suroeste-noreste del cadáver para musulmanes y judíos, mientras que los cristianos se rigen más por otras cuestiones como la disposición de las iglesias a las que se asocian, con una colocación genérica de oeste a este.

La ausencia de material que date el entorno funerario es una complicación añadida. En el caso de General Villalba 25, se han tomado dos muestras de carbono-14 de la madera de sendos tablazones de tumbas para contrarrestar dicha ausencia ${ }^{28}$. Como veremos, las fechas tardías resultan-

${ }^{25}$ Ruiz TABOAdA, «La necrópolis medieval del Cerro de la Horca».

${ }^{26}$ M. FIERro, «El espacio de los muertos: fetuas (fatwas) andalusíes sobre tumbas y cementerios», en L'urbanisme dans l'occident musulman au moyen âge: Aspects juridiques (Madrid 2000) págs. 153-190: 178; M. Chávet Lozoya, R. SÁnchez GaLlego y J. PAdial Pérez, «Ensayo de rituales de enterramiento islámicos en al-Andalus», AnMurcia 22 (2006) págs. 149-161: 152.

${ }^{27}$ Ruiz TABoada, La vida futura es para los devotos, pág. 24.

${ }^{28}$ Las maderas fueron secadas de forma progresiva en ambiente controlado y muestreados para las dataciones por radiocarbono. Muestras extraídas de las partes que 
tes sugieren que nos encontraríamos ante un área periférica del núcleo del cementerio judío, cuyas cronologías son más antiguas. Recordemos que en la tumba 101 del IES Azarquiel se documentó una moneda de Alfonso VII (1126-1157) ${ }^{29}$, fechando el conjunto en el siglo XII y años posteriores, mientras que estas muestras sitúan la fase judía entre los siglos XIII y XIV (Tabla I).

\begin{tabular}{|c|c|c|c|c|c|c|c|}
\hline \multirow{3}{*}{$\begin{array}{l}\text { Código } \\
\text { Direct AMS } \\
\text { D-AMS } \\
010915\end{array}$} & \multirow{3}{*}{$\begin{array}{l}\text { Muestra } \\
\text { T004 }\end{array}$} & \multirow{3}{*}{$\begin{array}{l}\delta\left({ }^{13} \mathrm{C}\right) \\
\text { per mil } \\
-25.8\end{array}$} & \multicolumn{2}{|c|}{ Fracción } & \multicolumn{3}{|c|}{ Edad } \\
\hline & & & $\mathrm{pMC}$ & $\begin{array}{l}1 \sigma \\
\text { error }\end{array}$ & BP & $\begin{array}{l}1 \sigma \\
\text { errol }\end{array}$ & CAL \\
\hline & & & 92.06 & 0.31 & 665 & 27 & $1330 \pm 43$ d. $C$ \\
\hline $\begin{array}{l}\text { D-AMS } \\
010916\end{array}$ & T052 & -29.6 & 90.19 & 0.30 & 829 & 27 & $1209 \pm 28$ d.C \\
\hline
\end{tabular}

Tabla I. Resultado de las muestras de carbono-14 de las tumbas 004 y 052.

\section{El límite sur del cementerio del Cerro de la Horca}

Los cementerios judíos solían estar delimitados por caminos o arroyos, lo que facilitaba su diferenciación de otros cementerios ${ }^{30}$. El aspecto del Cerro de la Horca hace mil años dista mucho del que presenta en la actualidad, saturado de edificios, parques y rotondas. El plano topográfico del Instituto Geográfico y Estadístico de 1900 muestra la orografía natural del entorno. La ladera que nos interesa posee una pendiente suave que discurre desde el antiguo camino de Madrid al suroeste hasta la Vega Norte de Toledo. La configuración de las curvas de nivel revelan la existencia de diferentes arroyos o escorrentías. Además, en el

supusieran menor deterioro se enviaron al laboratorio Direct AMS Radiocarbon Dating Service (http://www.directams.net/), radicado en Bothell, Washington (EEUU).

${ }^{29}$ Ruiz TABOAdA, «La necrópolis medieval del Cerro de la Horca», pág. 40.

30 J. CASAnovas Miro, «Las necrópolis judías hispanas», en Juderías y Sinagogas de la Sefarad medieval, eds. A. López Álvarez y R. IzQuierdo Benito (Cuenca 2003) págs. 493-533: 507. 
plano se identifica el antiguo camino de La Legua, por donde discurre parte de la actual calle General Villalba. Este paisaje permaneció inalterado hasta la planificación del ensanche norte de la ciudad a mediados del siglo XX.

En el supuesto de que el límite del cementerio siga criterios geográficos, parece razonable pensar que su cierre sur sería el mencionado camino de La Legua, una de las principales líneas de evacuación hídrica del cerro. Bajo esta premisa, vamos a analizar tanto los datos históricos como los arqueológicos provenientes de la excavación de los únicos solares publicados en esta zona, para ver si esta caracterización geográfica coincide con el registro conocido.

Con respecto a los datos históricos, algunas fuentes orientan sobre la localización de este cementerio, aunque no es objeto de este artículo profundizar en las mismas, pues merecen un capítulo aparte. Como ejemplo, Sánchez Rodríguez y Sánchez Rodríguez han publicado dos textos conservados en el Archivo Histórico Provincial que describen lindes con el cementerio judío del Cerro de la Horca ${ }^{31}$. El primero, de 8 de noviembre del año 1536, dice:

[...] baxammos por el camyno de la horca a dar al cerro de los Asateados [es el cerro frente del IES Azarquiel] que es frontero de la horca donde se fizo un moxon e dende dicho cerro bolvimos sobre mano yzquerda hazia Toledo deslindando los dichos hexidos con tierra de Villarreal y con el osario de los judios fasta dar en un valladar que esta cave el dicho osario alinde de tierra de Hernand Alvarez de Mesa;

y el segundo, de 1544, dice:

[...] fuymos deslindando los dichos exidos de Toledo que alindan con la Perdiguera que son heredad de Pablo Suso fasta dar en un valladar que esta cabe el onsario de los judios alinde de tierras de Fernan de Alva Vazquez de Mesa.

${ }^{31}$ F. SÁnchez Rodríguez y J. L. SÁnchez Rodríguez, «El cerro de la horca en la ciudad de Toledo: ubicación del cementerio judío, incumplimiento de la legislación del patrimonio y nueva puesta en valor con la aportación de nuevos datos», en Actas digitales del Congreso La Muerte en el Tiempo (Talavera de la Reina 2011) págs. 527543: 539. 


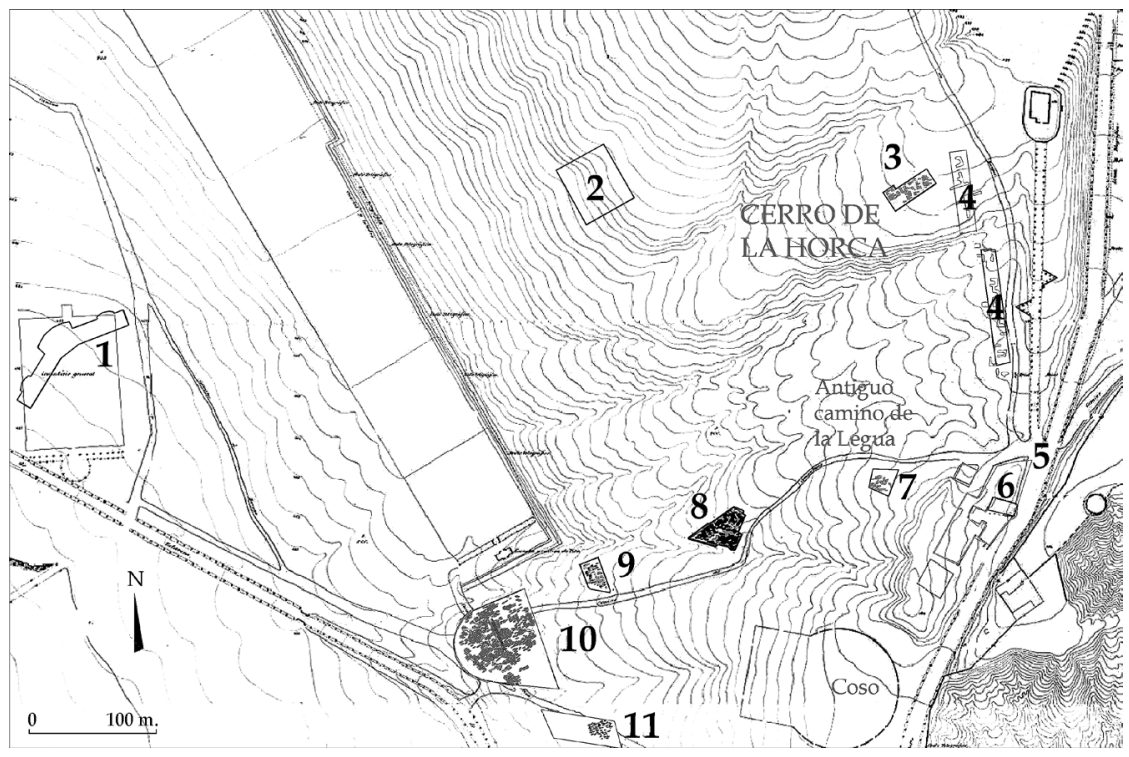

Figura 2: Proyección de las intervenciones mencionados en el texto sobre el plano topográfico del Instituto Geográfico y Estadístico de 1900, hoy IGNE (Archivo Municipal de Toledo), en relación con el antiguo camino de La Legua, asimilado con parte de la actual calle de General Villalba: 1. Antiguo cementerio municipal, Escuela de Magisterio y actual IES María Pacheco; 2. Pista deportiva del Colegio Infantes; 3. IES Azarquiel; 4. Excavaciones de Amador de los Ríos en la ladera oeste del camino del nuevo cementerio municipal; 5. Camino de Madrid; 6. San Eugenio; 7. General Villalba 20, 22 con el número 34 al este; 8. Valdivias Covarrubias; 9. General Villalba 25; 10. Quixote Crea, U2 del PERI de San Lázaro; 11. PERI San Lázaro U3, según PNOA 2012.

Pese a que en estos textos se habla de una valla o tapia, resulta complicado saber si se trata de su cierre histórico. En los últimos años se ha documentado este tipo de cierres en otros cementerios como el cristiano de Santa Leocadia de Afuera y el musulmán del circo romano ${ }^{32}$; futuros hallazgos arqueológicos nos dirán si el judío contaba también con similar demarcación.

Con respecto a su adscripción cultural, aunque el cementerio se caracteriza por la ausencia circunstancial de corpus epigráfico o materiales en contexto arqueológico que lo relacionen con el mundo judío, la publicación de diferentes trabajos ha permitido ampliar la informa-

\footnotetext{
${ }^{32}$ Ruiz TaboadA, «Comments».
} 
ción existente, centrando el debate en el análisis de su límite sur, zona de contacto con otros cementerios localizados en sus inmediaciones. Entre ellos, destacan las excavaciones de General Villalba 20, 22 y 30, Valdivias Covarrubias y Quixote Crea (U2 del PERI de San Lázaro). Además, disponemos de los datos del IES Azarquiel (años 2008 y 2009), las noticias de aparición de supuestas tumbas judías durante la segunda mitad del siglo XX en las obras de construcción tanto de la Escuela de Magisterio (actual IES María Pacheco) en 1959, como del Colegio Infantes en $1979^{33}$, y las excavaciones fortuitas de finales del XIX y prospecciones programadas de inicios del XX en el camino del cementerio ${ }^{34}$.

Atendiendo a la dispersión de estos restos arqueológicos en el entorno, no sólo se puede inferir un área de necrópolis judía en torno a los 22.250 $\mathrm{m}^{2}$, lo que constituiría una imponente ciudad de los muertos, sino que, por primera vez, es posible establecer el grado de relación con otros lugares de enterramiento limítrofes como el Taifa del camino de Madrid o el cristiano de la ermita de San Eugenio (fig. 2).

En ninguna de las intervenciones recientes, salvo el IES Azarquiel, se identifica claramente el cementerio judío. No obstante, sí se sugiere dicha existencia en las menciones al Colegio de Infantes, Escuela de Magisterio y, sobre todo, el camino del nuevo cementerio municipal. En esta última, Rodrigo Amador de los Ríos -de forma algo intuitiva aunque premonitoria-, no sólo identifica el cementerio judío sino el musulmán de época Taifa que limita con él. Además, detecta posibles destrucciones de tumbas musulmanas por parte de judías, e incluso de cristianas sobre estas últimas, relacionadas con los cementerios asociados a los numerosos hospitales existentes en la zona. En su estudio recopila parte de la información histórica existente sobre el Cerro de la Horca y da las claves arqueológicas para reconocer diferentes cementerios en la zona. El judío lo asocia a dos inscripciones hebreas, la primera descubierta en $1887^{35}$ durante el acondicionamiento

\footnotetext{
${ }^{33}$ Gómez Menor, «Algunos datos sobre el cementerio judío de Toledo», y A. LóPez Álvarez, «Nuevas noticias sobre el cementerio judío de Toledo», Sefarad 39:1 (1979) págs. 120-122.

${ }^{34}$ Amador de los Ríos, «Excavaciones en Toledo».

${ }^{35}$ Amador de los Ríos, «Excavaciones en Toledo», pág. 14. 
del camino del actual cementerio municipal (posiblemente antiguo camino de la Horca del que hablan las fuentes), la segunda hallada durante sus excavaciones a inicios del siglo $\mathrm{XX}^{36}$, en el reverso de un cipo funerario andalusí del que luego hablaremos. Además, este autor relaciona con el mundo judío un tipo de tumba con cierre abovedado, y lo referencia a similares descubrimientos relatados por Pedro Salazar de Mendoza en el siglo XVI con motivo de la construcción del Hospital de San Juan Bautista o de Afuera, con todas las reservas que ello conlleva. Incluso el hecho de que en estas crónicas se hable de enterramientos con dos bovedillas, le hace cuestionar su veracidad ${ }^{37}$. Con estos datos, Rodrigo Amador de los Ríos concluye:

Inclina todo, pues, a sospechar -aunque es sabido que las piedras viajan- pudo ser aquel lugar un tiempo de enterramiento de los judíos toledanos después de la Reconquista, quizá hasta la fecha memorable de la expulsión de la expresada grey ${ }^{38}$.

Por desgracia, el resto de publicaciones posteriores no interpretan el ritual de enterramiento en su conjunto, reconociendo vagamente la existencia de diferentes prácticas funerarias relacionadas con las tres religiones pero refugiándose en el término mudéjar para explicar la enorme concentración de enterramientos documentados.

El análisis tanto de la distribución de tumbas, su orientación y su descripción tipológica permite establecer ciertos rasgos comunes para todas ellas, al contrastarlos con los resultados obtenidos tanto en la excavación del IES Azarquiel como otras excavaciones cercanas descritas en este artículo y con las tipologías clásicas de este tipo de necrópolis en el resto de España. Como veremos, tienen especial protagonismo en este planteamiento tres localizaciones: la ermita de San Eugenio y su posible cementerio, en la confluencia de los caminos de La Legua y Madrid, el cementerio Taifa de este último y el cementerio judío del camino de la Horca (fig. 1).

${ }^{36}$ Amador de los Ríos, «Excavaciones en Toledo», pág. 21.

${ }^{37}$ Amador de los Ríos, «Excavaciones en Toledo», pág. 16. Enterramientos con dos bovedillas o lucillos han sido documentados arqueológicamente un siglo después, en las excavaciones del IES Azarquiel.

${ }^{38}$ Amador de los Ríos, «Excavaciones en Toledo», pág. 25. 
El primer caso analizado es el de la excavación de los números 20 , 22 y 34 de General Villalba ${ }^{39}$. En los números 20 y 22 destaca el hecho de que no se hayan identificado -al menos claramente-, ni enterramientos musulmanes ni cristianos, pese a su cercanía con San Eugenio y al camino de Madrid. No obstante, la presencia de madera ejerciendo de cierre subterráneo y de lucillos recuerda más a las tumbas judías identificadas en el IES Azarquiel. Además, los dos cuerpos en decúbito lateral derecho con cierre subterráneo de lajas ${ }^{40}$ se pueden relacionar con el cementerio Taifa del camino de Madrid. Algo similar ocurre con el número 34, aunque según el mismo excavador, sólo se pudo documentar el fondo de alguna tumba, al ser el yacimiento arrasado con medios mecánicos, previo a su excavación con metodología arqueológica. Los escasos individuos documentados en cotas inferiores, por la profundidad a la que aparecen y colocación, apuntan a su pertenencia a la necrópolis judía (Tabla II).

\begin{tabular}{|c|c|c|c|c|c|c|c|}
\hline & $\begin{array}{l}\text { Superficie } \\
\text { excavada }\end{array}$ & $\begin{array}{c}\text { Número } \\
\text { de tumbas }\end{array}$ & Sector & Cronología & \multicolumn{2}{|l|}{ Ritual } & Lucillo \\
\hline $\begin{array}{l}\text { Valdivias/ } \\
\text { Covarrubias }\end{array}$ & $680 \mathrm{~m}^{2}$ & 287 & Límite sur & s. XI-XV & Indeterminado & - & Sí \\
\hline Villalba 25 & $290 \mathrm{~m}^{2}$ & 75 & Límite sur & $\begin{array}{c}\text { s. X-XI } \\
\text { s. XIII-XV }\end{array}$ & $\begin{array}{c}\text { Musulmán } \\
\text { Judío } \\
\text { Indeterminado }\end{array}$ & $\begin{array}{c}22 \\
51 \\
2\end{array}$ & No \\
\hline Azarquiel & $300 \mathrm{~m}^{2}$ & 107 & Central & s. XII-XV & Judío & 107 & Sí \\
\hline $\begin{array}{l}\text { San Lázaro } \\
\text { U2 Quixote }\end{array}$ & $5.514 \mathrm{~m}^{2}$ & 794 & Límite sur & s. XI-XIV & Indeterminado & - & No \\
\hline Villalba 20,22 & $246 \mathrm{~m}^{2}$ & 36 & Límite & - & Indeterminado & - & $\overline{\text { Sí }}$ \\
\hline Villalba 34 & $215 \mathrm{~m}^{2}$ & $9 ?$ & sureste & - & Indeterminado & - & - \\
\hline
\end{tabular}

Tabla II: Intervenciones arqueológicas mencionadas en el texto, en el entorno del cementerio judío del Cerro de la Horca.

Los datos publicados en sendas excavaciones de Valdivias Covarrubias y del auditorio Quixote Crea (U2 del PERI de San Lázaro) resultan igual de complejos de analizar, aunque la documentación fotográfica que aportan permite relacionarla con el resto de los datos

${ }^{39}$ Rodríguez Untoria, «Excavación arqueológica». Agradezco a Santiago Rodríguez Untoria la información aportada sobre estas excavaciones.

${ }^{40}$ RodríGuez Untoria, «Excavación arqueológica», pág. 17. 
existentes para esa zona. En el primer caso, la ocupación del espacio se caracteriza por una gran saturación de tumbas, con orientaciones diversas y mezcla de unas con otras (Tabla II). La distribución general de fosas permite identificar, al menos, dos tipos de tumbas en función de su orientación: unas similares a aquellas relacionadas con las tumbas judías del IES Azarquiel, con la existencia además de una estructura cuadrangular similar a las documentadas en ese yacimiento ${ }^{41}$. Una segunda orientación que puede estar en relación con la ermita de San Eugenio, al estar los cuerpos alineados con el ábside de la iglesia y, por tanto, de tradición cristiana. Aunque sus excavadores también identifican enterramientos de rito musulmán, no se aporta ninguna planimetría que los contextualice (fig. 4). El análisis tanto de los individuos como del tipo de tumba que se describe en el artículo, apunta a la presencia de tumbas profundas en covacha lateral, algún lucillo y cierre subterráneo de madera, identificables con el ritual judío, y de antropomorfas más superficiales, asimilables con el cristiano, con las reservas que merece esta interpretación y a expensas de la publicación de la memoria final de los resultados ${ }^{42}$.

La excavación de la U2 del PERI San Lázaro (Quixote Crea) plantea similares problemas de interpretación (Tabla II), con parecido índice de saturación de tumbas que Valdivias Covarrubias ${ }^{43}$. En la información publicada se reconocen tumbas profundas asumibles al ritual judío con ausencia de lucillos, y tumbas musulmanas, sin que se haya identificado claramente ninguna de tradición cristiana. Sus excavadores recurren al término mudéjar para definir este entorno funerario ${ }^{44}$.

En resumen, esta distribución caótica y saturada de tumbas es lo que define al límite sur del cementerio del Cerro de la Horca: hemos

${ }^{41}$ RuIz TABOAda, La vida futura es para los devotos.

42 Requejo López y Maqueda García-Morales, «Excavaciones». Lo que sí resulta llamativo es que esta orientación de tumbas no se ha documentado, al menos no de forma tan homogénea, en ninguna excavación del entorno, lo que abre una nueva línea de investigación para tratar de delimitar y definir en un futuro, el cementerio de San Eugenio, u otros cementerios asociados con los hospitales del entorno como y lo sugirió en su día Amador de los Ríos («Excavaciones en Toledo», pág. 28).

${ }^{43}$ Agradezco a Elena Rosado Tejerizo su disponibilidad e información aportadas.

${ }^{44}$ Rodríguez Fernández y RosAdo TeJERIzo, «Excavación arqueológica». 
visto como en Valdivias Covarrubias confluyen, al menos, dos rituales de enterramiento diferentes, y en la U2, al menos, otros dos, patrón que se va a repetir parcialmente, en el número 25 de General Villalba.

Por último, la intervención en General Villalba $25^{45}$ ha dado como resultado el descubrimiento y documentación de 75 tumbas (fig. 3). Además, se han planteado 10 sondeos estratigráficos para comprobar tanto la ausencia de enterramientos en aquellos lugares en los que aparentemente no existían fosas, como para conocer la caracterización geológica de su subsuelo. Mientras que la mayoría de sondeos excavaron el nivel geológico o alcaén y dieron negativo en tumbas, en tres de ellos (sondeos 1, 2 y 10) se pudo documentar el sedimento de un paleocauce correspondiente a un pequeño arroyo que bebía formar parte de la escorrentía natural. Este arroyo, en origen, debió dividir el espacio de enterramiento en dos sectores (fig. 5, núm. 1). El primero, localizado al norte, que concentra la mayoría de tumbas identificadas como judías, mientras que el segundo al sur, que mantiene la presencia de tumbas judías alterando tumbas más antiguas de rito musulmán. En la zona de confluencia entre ambos sectores que coincide además con el arroyo, se aprecia una saturación del espacio cementerial, con la consecuente destrucción de las tumbas más antiguas (musulmanas) por las más modernas (judías). Así, se han excavado 22 tumbas musulmanas concentradas en el sector sur frente a las $\mathbf{5 1}$ judías repartidas por toda la superficie, además de 2 tumbas indeterminadas, localizadas en el sondeo 10 (T-024 у Т-027).

Los resultados de esta excavación permiten desarrollar y matizar los casos analizados anteriormente. Como veremos, se ha podido delimitar tanto la zona de influencia de la necrópolis Taifa del camino de Madrid (Fase andalusí), como la expansión del cementerio judío hacia el sur (Fase judía), con una cronología ligeramente posterior a la documentada en su sector central (IES Azarquiel). Se constata

${ }^{45}$ En la excavación han participado las arqueólogas Beatriz Martín Eguiguren y Cristina Sierra y la antropóloga física Isabel Molero, desarrollada entre septiembre y noviembre de 2014, con autorización de la Dirección Provincial de Toledo, Consejería de Educación Cultura y Deportes. Los materiales -incluidos los óseos- se han depositado en el Museo Arqueológico Regional de Santa Cruz de Toledo. 


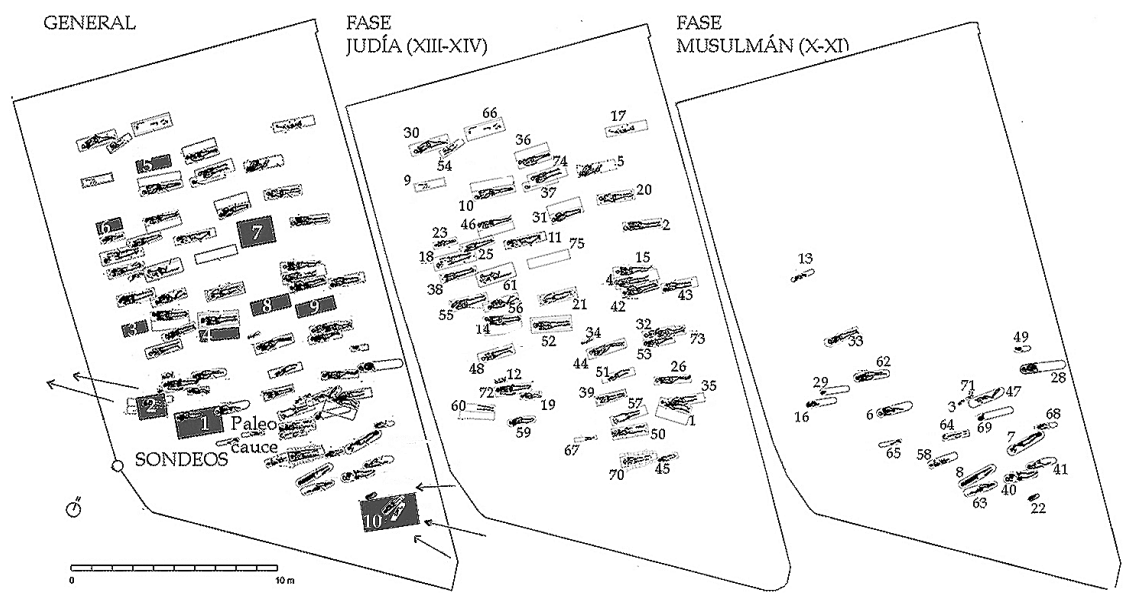

Figura 3: Fases de ocupación de General Villalba 25 con la trayectoria del paleo-cauce y sondeos realizados.

además la ausencia de tumbas cristianas y, en relación a cuestiones meramente tipológicas, se documenta una reducción del uso de lucillos conforme nos alejamos del sector central, con su ausencia en los solares más al suroeste como la propia General Villalba 25 o Quixote Crea (U2 del PERI de San Lázaro), frente a su presencia residual en solares como Valdivias Covarrubias o General Villalba 20 y 22.

\subsection{La fase andalusi}

La primera ocupación del suelo de General Villalba 25 se corresponde con la excavación de 22 tumbas de rito musulmán en torno a un primitivo arroyo que debía formar parte de una de las líneas de escorrentía del cerro (fig. 5, sondeo 1). De este cementerio Taifa, tenemos noticia por fuentes históricas, lápidas y por las excavaciones llevadas a cabo a principios del siglo pasado por Rodrigo Amador de los Ríos ${ }^{46}$. Aunque existen pocos datos publicados, el cementerio se distribuiría en torno al camino de Madrid y a lo largo de la ladera oeste del mismo, limitando al norte con el Cerro de la Horca. Conforme se avanza en el conocimiento

\footnotetext{
${ }^{46}$ Amador DE Los Ríos, «Excavaciones en Toledo».
} 


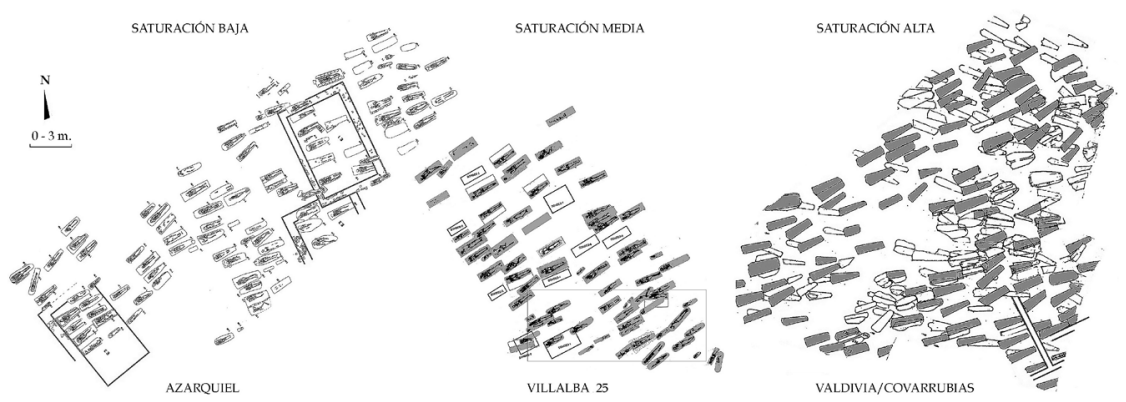

Figura 4: Distribución de tumbas en de tres de los solares analizados en el texto:

IES Azarquiel $^{47}$, General Villalba 25 y Valdivias Covarrubias ${ }^{48}$.

arqueológico del entorno, el antiguo camino de La Legua, actual calle General Villalba se va consolidando como el límite físico de ambas necrópolis. En este sentido, los micro cauces que se distribuyen por la ladera, uno de ellos contextualizado en la excavación (fig. 3), deben ser también orientativos para comprender el comportamiento de dicho límite. Con las lógicas reservas, la vertiente norte del camino sería la ocupada por el cementerio judío, mientras la sur por el musulmán (fig. 2, núm. 11).

Las tumbas de esta fase no presentan cierre subterráneo alguno y, por desgracia, tampoco se ha localizado ningún resto de ajuar asociado a ellas. Los enterramientos son en fosa simple poco profunda (en torno a los 80 $\mathrm{cm}$ de media), con el individuo en semi-decúbito lateral derecho con las piernas flexionadas, brazos normalmente juntándose delante de la pelvis y cabeza orientada al sureste (fig. 5, T-049 y T-062), aunque también se ha localizado alguna tumba con un grado de flexión lateral más vertical y el cuerpo, por tanto, más agrupado (fig. 5, T-033). Este ritual se asocia al mundo andalusí y se relaciona con tumbas de similares características también documentadas en el entorno, como la U3 del PERI de San Lázaro (fig. 2, núm. 11) ${ }^{49}$. Desde un punto de vista cronológico, la única referencia

\footnotetext{
${ }^{47}$ Ruiz TABoAda, «La necrópolis medieval del Cerro de la Horca».

${ }^{48}$ Rodríguez Fernández y Rosado TeJerizo, «Excavación arqueológica»: planta de Valdivias Covarrubias, modificada para resaltar las dos alineaciones discordantes.

${ }^{49}$ Agradezco a Rafael Caballero y Elena Sánchez Peláez, de Novas Arqueología, la información aportada a este respecto.
} 
en contexto arqueológico la encontramos en este último solar, en el que la empresa Novas Arqueología excavó en 2010 la tumba 32, en la que apareció una moneda Taifa de mediados del siglo XI (fig. 5, núm. 2). Además, también contamos con cipos o demarcaciones verticales de tumbas pertenecientes a este cementerio fechados en la misma época, aunque descontextualizados.

Llama a atención la posición semi-flexionado de la mayoría de los cuerpos que contrasta con el decúbito lateral estricto de otras necrópolis toledanas como la del Circo Romano ${ }^{50}$. Esto puede responder tanto a la evolución en la forma de enterrar que esta comunidad pudo experimentar a lo largo del tiempo, como a una cuestión cronológica, puesto que la datación que se maneja para esta necrópolis es el siglo XI, frente a los siglos VIII a X de la del circo $^{51}$.

Como hemos mencionado, las fosas no suelen ser muy profundas y se concentran en torno al cauce del primitivo arroyo que discurría por ese sector de ladera. Desde un punto de vista de conservación, la mayoría se encuentran parcialmente arrasadas o cortadas por la excavación de las fosas asociadas con la fase judía de ocupación, más profundas que las musulmanas (fig. 5, T-013, T-016 y T-033). Esto entraría en conflicto con uno de los principales prefectos teóricos en cuanto a la ubicación de los cementerios judíos al que aludíamos antes, puesto que su elección debe responder a la limpieza y falta de uso del suelo. No obstante, el purismo de esta norma puede verse condicionado al más que probable desconocimiento de la existencia de un cementerio previo por parte de los judíos que deciden enterrarse allí o a la simple indiferencia. Es de suponer que cuando se produce la expansión hacia el sur del cementerio judío, las tumbas andalusíes ya estarían desprovistas de su delimitación superficial, lápidas algunas de ellas reutilizadas con posterioridad en tumbas judías. Como ejemplo de esta reutilización, contamos con el cipo funerario en mármol gris perteneciente al visir Abu Umar Musà, fechado en el año

\footnotetext{
${ }^{50}$ RuIZ TABOADA, «Comments».

${ }^{51}$ A. RuIz TABoAda, «La muerte en el Madrid andalusí», en Actas de las X Jornadas de Arqueología de la Comunidad de Madrid (2014) págs. 47-71, y «Comments».
} 
$1073^{52}$, asociado a este cementerio del camino de Madrid $^{53}$ que, ya incompleto, fue reaprovechado como lápida horizontal de una tumba judía, incluyendo en su reverso la inscripción en hebreo «Meir hijo de Yahuda Djanaj, su alma [está] en el Edén», datada en el siglo XII (fig. 5, núm. 4) ${ }^{54}$. Ello prueba la constante transformación a la que ha estado y sigue estando sometido este espacio a lo largo de la historia.

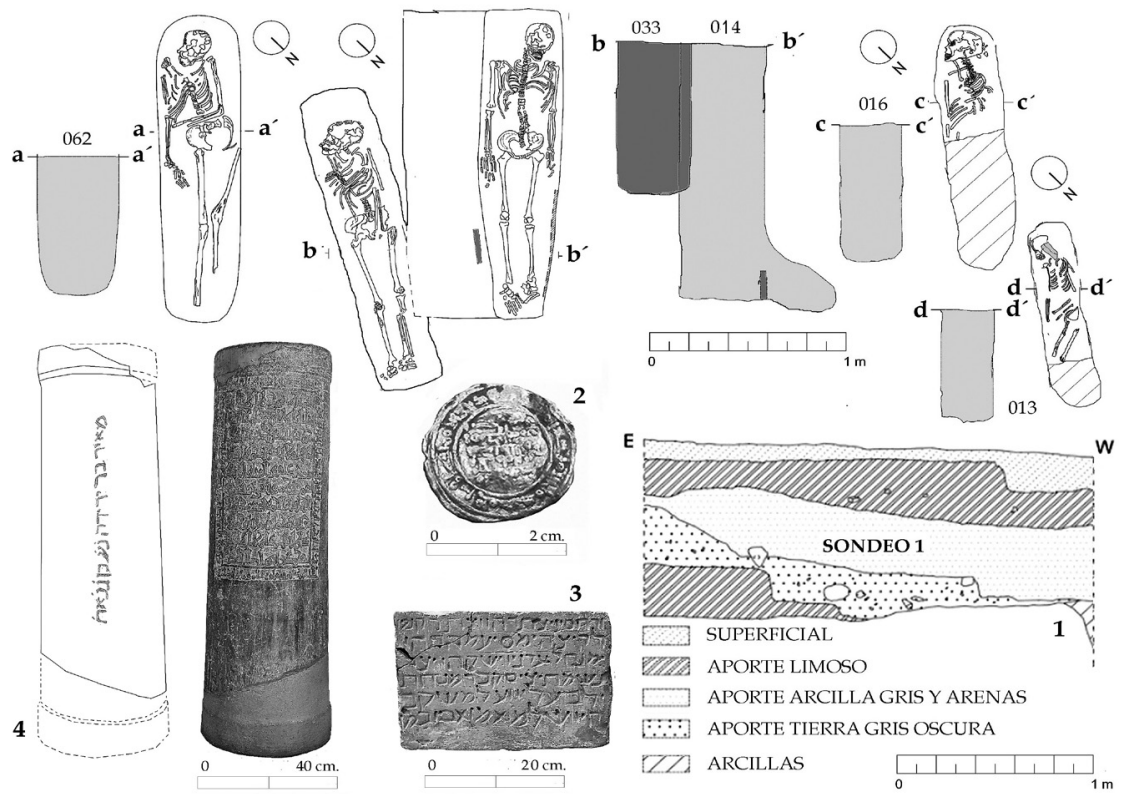

Figura 5: Diversos tipos de tumbas descritas en el texto, relacionadas con el ritual de enterramiento musulmán. 1. Estratigrafía de los aportes sedimentarios del paleocauce que recorre el yacimiento (Sondeos 1, 2 y 10); 2. Dinar de la U3 del PERI de San Lázaro (parcela medianera sur del Quixote Crea; fuente: página web de Novas Arqueología); 3. Ladrillo funerario judío de la venta de la Esquina (Museo Sefardí de Toledo. Foto: Arturo Ruiz Taboada); 4. Anverso y reverso del cipo funerario del visir Abu Umar Musá (57478-ID001 Museo Arqueológico Nacional. Foto: Ángel Martínez Levas, N.I. 57478).

${ }^{52}$ E. Gómez Ayllón, Inscripciones árabes de Toledo: Época islámica. Tesis Doctoral, Universidad Complutense de Madrid (2006) págs. 295-301; F. García MARTín, La comisión de Monumentos de Toledo (1875-1931). Vol. II (Toledo 2010) págs. 192-193.

${ }^{53}$ Amador de los Ríos, «Excavaciones en Toledo», pág. 21.

${ }^{54}$ D. Botella Ortega y J. Casanovas Miró, «El cementerio judío de Lucena (Córdoba)», MEAH. Sección Hebreo 58 (2009) págs. 3-25: 11. 


\subsection{La fase judia}

Los enterramientos se localizan por toda la superficie excavada y se relacionan con el cementerio judío que se distribuye por la ladera al norte del camino de La Legua (fig. 2). Como veremos, los 51 individuos de este rito están en decúbito supino con la cabeza al frente -en ocasiones caída hacia un lado u otro según tendencia, determinado por su desconexión anatómica-, brazos estirados o ligeramente flexionados, y piernas estiradas, una estirada y otra ligeramente flexionada o flexionadas. La gran mayoría de ellos presenta almohadilla bajo cráneo.

Estos enterramientos concentran los únicos restos de ajuar documentados en las dos fases del yacimiento (fig. 6). La muestra consta de un anillo de bronce de pequeñas dimensiones con una pieza porosa incrustada, procedente del dedo meñique del individuo de la T-009, además de un pendiente de bronce con ónix ${ }^{55}$, documentada en contextos funerarios como Tárraga ${ }^{56}$. Se asocia con José a la que otorga el poder de conceder el éxito en la sociedad ${ }^{57}$. Un juego de pendientes de un individuo infantil (T023), dos pendientes de bronce localizados en la T-057 y otro con bola de plata de la T-031. Además, se han localizado varios alfileres, casi todos en la zona de la mandíbula (T-004, T-005, T-046 y T-057). No obstante, entre los hallazgos más llamativos se encuentra lo que parece ser un colgante relicario. La pieza posee forma amigdaloide y consta de dos láminas en su momento unidas por bisagra y cierre. Está decorado mediante círculos concéntricos en su anverso y reverso, y en sus paredes interiores se repite la misma decoración esquemática a base de semicírculos, sin un significado aparente ${ }^{58}$. Dentro conservaba restos de tela (fig. 6, T-066).

${ }^{55}$ E. CANTERa Montenegro, «Los judíos y las ciencias ocultas en la España medieval», La España Medieval, 25 (2002) págs. 47-83: 59.

56 A. Colet, J. Muntané, J. Ruiz, O. Saula y E. Subira de Galdácano, «Les fosses communes des Roquetes a Tárrega», en L'Archéologie du judaïsme en France et en Europe, eds. P. Salmona y L. Sigal (Paris 2011) págs. 247-260: 251.

${ }^{57}$ M. N. GonZÁlez Fresneda, Atuendo, aderezo, pócimas y ungüentos femeninos en la Corona de Castilla (siglos XIII y XIV). Tesis Doctoral, Universidad Complutense de Madrid (2013) pág. 907.

${ }^{58}$ Agradezco a Jordi Casanovas, Isabel Molero, Sandra Azcárraga, Carmen Álvarez, Beatriz Martín Eguiguren, Javier Castaño, Gema Alonso y Santiago Palomero los comentarios hechos a este respecto. 
Un pendiente con decoración y forma parecidas se ha documentado en la tumba 217 de la cercana Valdivias Covarrubias ${ }^{59}$. Resulta complicado hacer una interpretación de su significado, aunque recordemos que la lucha contra el mal de ojo está presente en las tres religiones medievales, incluida la judía ${ }^{60}$. Desde un punto de vista cronológico, estos adornos, lejos de ser representativos de un momento concreto, son diseños comunes que se repiten durante la Edad Media ${ }^{61}$.



Figura 6: Elementos de adorno personal y relación de tumbas en los que aparecen.

Con respecto al diseño de las tumbas, la tipología es propia del contexto del cementerio judío, a la que se suman dos nuevas: las de covacha lateral y las escalonadas con cubierta de madera. Las de covacha o cámara lateral, pese al escaso número de la muestra, son posiblemente las más representativas por ser la primera vez que se documentan en contexto arqueológico en esta zona, relacionadas con el ritual judío de enterramiento (T-001, T-010, T-014, T-015, T-031, T-035, T-036 y T-046). En este sentido, se han inventariado diversos tipos, siendo una de las más llamativas la T-015, al contar con una fosa más ancha de lo normal que alberga dos cuerpos, en cuyo lateral se excava la covacha, sellada por un murete de mampostería sin trabar. El tercer cuerpo presenta un

${ }^{59}$ Requejo López y Maqueda García-Morales, «Excavaciones», pág. 738.

${ }^{60}$ J. Pablo Bubello, «Magia y polémicas antimágicas en la España bajo medieval Enrique de Villena, su tratado de fascinación o de aojamiento y los límites de la ortodoxa cristiana», Prohistoria 17, vol. XV (2012) págs. 1-24: 10 y 11.

${ }^{61}$ De Juan, Los enterramientos musulmanes, pág. 39; GonZÁlez Fresneda, Atuendo, aderezo, pócimas, pág. 843. 
desplazamiento anatómico lateral consecuencia de haber sido empujado al interior en el momento de su enterramiento (fig. 7, T-015). Esta covacha ha generado además gran cantidad de información sobre los procesos post-deposicionales a los que ha estado sometida, al documentarse en estratigrafía, el hundimiento de la misma, con el consiguiente aplastamiento de la zona del tórax del individuo sepultado en ella (fig. 7). La fosa, de algo más de un metro de ancho por dos y medio de largo y metro treinta de profundidad, cuenta con dos cuerpos más, individualizados por maderas y cerrados con sendos tablazones (fig. 7, T-004 y T-042). Este tipo de fosas amplias que albergan más de un cuerpo han sido documentadas en el IES Azarquiel, conteniendo sendos cuerpos, distribuidos a distintas alturas ${ }^{62}$. Este último se ha relacionado con usos familiares del espacio funerario.

Es de suponer que la inhumación de ambos individuos se produjo tras el sellado de la covacha. Más difícil resulta establecer el momento de su enterramiento, si es contemporáneo del individuo de la T-015, o existe un lapso de tiempo. La primera de las hipótesis no plantea ningún problema, al preparar sendas tumbas con sus respectivos cierres subterráneos y rellenar la fosa. La segunda en cambio, requeriría de la reapertura de la fosa original, su excavación hasta el nivel del cierre de la covacha, la preparación de los cuerpos y su posterior colmatación, acto que, entre otras cosas, demandaría de una perfecta delimitación superficial de la tumba para no alterar la estructura subterránea de la covacha en su re excavación.

La tumba 004 de este conjunto se fecha por carbono-14 en el siglo XIV (Tabla I), lo que pudiera orientar sobre la introducción en Toledo de este tipo de estructuras, ausentes hasta el momento en los sectores centrales del cementerio y generalizadas en sus áreas limítrofes como Valdivias Covarrubias. No obstante, esta hipótesis debe ser sometida a constante revisión. La presencia o ausencia de cámaras laterales en diferentes zonas del cementerio puede responder más a una cuestión de preferencia de uso por parte de la comunidad, que a una cuestión estrictamente cronológica, al estar documentadas ya desde el siglo $\mathrm{X}^{63}$.

${ }^{62}$ Ruiz Taboada, La vida futura es para los devotos, pág. 97, fig. 131, tumbas 63a y b.

${ }^{63}$ Botella Ortega y Casanovas Miró, «El cementerio judío de Lucena (Córdoba)», pág. 15. 

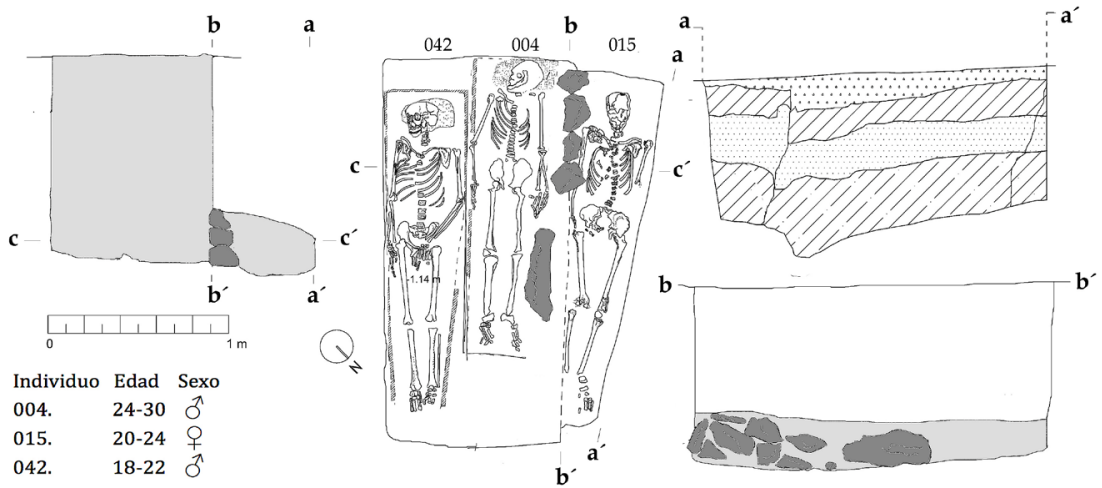

Figura 7: Estudio de detalle de la fosa que contiene en su fondo dos individuos y un tercero en el interior de su cavidad lateral. Alzado del cierre de la cavidad lateral y estratigrafía del colapso de la covacha.

Un segundo ejemplo de covacha lo encontramos en la T-001. En este caso la fosa estaba colmatada de mampuestos de medio y gran tamaño ejerciendo de sello, cuya proporción es mayor conforme nos aproximamos al fondo de la fosa y, por tanto, al acceso a la covacha. Las piedras están sin labrar salvo un fragmento de molino de granito. Esta muela no aporta cronología por ser su diseño bastante común para la época. Como dato recordar que estos mampuestos de granito no son autóctonos de la zona, lo que implica su recolección y acopio (fig. 8, T-001).

Por último, señalar que la covacha está mínimamente alterada por una segunda fosa. La disposición de ambas es paralela, de lo que se deduce que no existía intención de dañar la más antigua (fig. 8, T-035).

El resto de covachas no presentan cierre subterráneo. En alguna de ellas se han documentado maderas que pueden relacionarse con su cierre lateral, aunque este supuesto es más complejo de demostrar debido al alto grado de deterioro de las mismas, además de un único ladrillo asociado al cierre en la tumba 014 (fig. 5).

Este tipo de cámaras viene siendo común en los cementerios asociados al rito judío peninsular como Montjüich o Lucena ${ }^{64}$. Salvo los dos casos descritos (T-001 y T-015), la ausencia de cierres materiales claros

${ }^{64}$ Botella Ortega y Casanovas Miró, «El cementerio judío de Lucena (Córdoba)», pág. 15. 


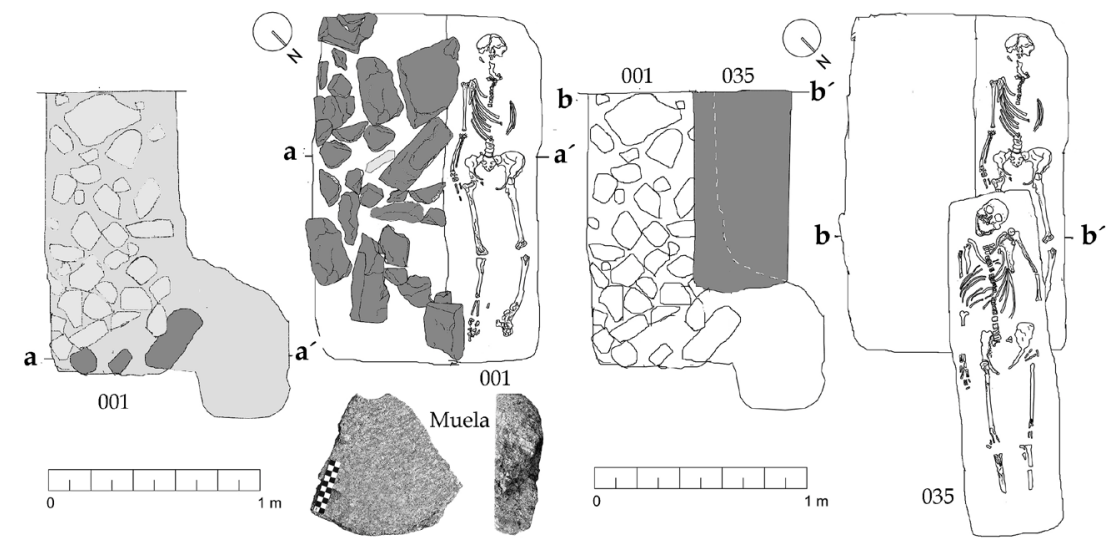

Figura 8: Tumba 001 de covacha y su relación con la T-035 de fosa simple.

en la mayoría de estas covachas puede dificultar su identificación, hecho a tener en cuenta a la hora de plantear futuras excavaciones en esta zona.

Un segundo tipo de tumba es la escalonada ${ }^{65}$ excavada en el geológico con tablazón que ejerce de cierre (fig. 9, T-052 y Tabla I, T-021. T-061 y $\mathrm{T}-066) \mathrm{u}$ otras en las que es la madera lateral que forra los laterales de la tumba la que pudiera sustentar una tablazón encima como cierre subterráneo (T-004, T-005 [vid. fig. 9], T-018, T-025, T-037, T039 y T-042). Como veremos, la interpretación de la madera en contextos funerarios genera bastante controversia.

La anomalía de este muestrario la tenemos en una tumba con el nivel inferior con fábrica de ladrillo y cubierta de madera, de planta trapezoidal (fig. 9, T-070). En el interior se identifica el contorno de lo que parece un ataúd. Una tumba en fábrica de ladrillo parcial de planta trapezoidal y posiblemente con cubierta de madera fue también documentada en el IES Azarquiel ${ }^{66}$. Un murete de ladrillo completaba su planta trapezoidal, excavada parcialmente en el geológico en un intento de simular simetría. Algo parecido pudo ocurrir con la tumba 070 de General Villalba 25, debido a que su localización en pleno paleo-cauce y, por tanto, con sedimento

${ }^{65}$ Este escalonamiento está también documentado en el sector central asociado a bóvedas de ladrillo o lucillos; RuIz TABOADA, «La necrópolis medieval del Cerro de la Horca», pág. 31.

${ }^{66}$ Ruiz TABOADA, «La necrópolis medieval del Cerro de la Horca», pág. 88. 
poco estable, motivó la necesidad de dar consistencia a sus paredes, mediante la fabricación de esa estructura trapezoidal de ladrillo.

El resto son fosas simples de mayor o menor profundidad, llegando a alcanzar en algunos casos el metro ochenta-dos metros, algunas de ellas con presencia de madera que asociamos con algún tipo de delimitación o cierre, y que la lógica obliga a considerarlos como restos de ataúd. Pese a que en algunos casos la disposición de la madera apunte al uso de estos últimos, esta excavación no cuenta con los suficientes datos materiales conservados que lo corroboren. No obstante, y dado el gran número de ataúdes que se han documentado en el sector central de este mismo cementerio ${ }^{67}$, conviene recordar la posibilidad incluso de manipular diversas partes del mismo para que el individuo termine en contacto con la tierra virgen ${ }^{68}$. De hecho, resulta cuanto menos llamativo que tanto en el IES Azarquiel como en este yacimiento se hayan conservado más tapas que fondos de estas cajas. Además de estas estructuras, venimos describiendo una gran cantidad de tablas asociadas al cierre subterráneo de las tumbas, que la bibliografía suele identificar con angarillas. Es en muchos casos muy difícil determinar la funcionalidad de la estructura de madera que se encuentra asociada a los cuerpos. En según que circunstancias ya hemos visto como los arqueólogos recurrimos a términos como parihuela o ataúd. Mientras que la identificación de las primeras parece más responder a una moda de cita bibliográfica, sin que exista prueba material real de su presencia en tumba, la identificación de ataúdes genera mayor controversia.

Estos contenedores de cadáveres los encontramos indistintamente en las tres religiones, pese a que, como hemos visto en la judía, teóricamente su uso no resulta del todo canónico. Lo mismo ocurre con ataúdes asociados a tumbas musulmanas, aunque su empleo sí podría estar justificado en tumbas más recientes de supuesto rito malikí, que pudieran recibir influencias de otras tradiciones regionales ${ }^{69}$. Por último, los cristianos parece que son los únicos que lo aprueban abiertamente, aunque no todas

${ }^{67}$ RuIz TABOADA, «La necrópolis medieval del Cerro de la Horca», pág. 31, y La vida futura es para los devotos, pág. 73.

${ }^{68}$ J. CAsanovas Miró, «La arqueología funeraria judía en el marco de la arqueología de la muerte», en Jornadas sobre Antropología de la muerte. Identidad, creencias y ritual ([Madrid] 2012) págs. 44-63: 58; R. KashanI, «Burial in Post-Biblical Time», en Encyclopaedia Judaica. Second Edition, ed. F. SKolnIK (Detroit 2007) pág. 293.

${ }^{69}$ FIERro, «El espacio de los muertos», pág. 180. 
las tumbas contienen ataúd de madera, condicionado más por el poder adquisitivo de los difuntos que por cuestiones de rito, y generalizándose su uso en siglos posteriores por temas sanitarios ${ }^{70}$.

No menos compleja es la interpretación de los clavos asociados a la madera en el interior de muchas de estas tumbas. En este yacimiento se han documentado un total de 22 tumbas con clavos (T-002, T-004, T-005, T-009, T-010, T-011, T-012, T-018, T-020, T-021, T-030, T-038, T-039, T-043, T-050, T-052, T-053, T-054, T-055, T-057, T-066 y T-073). El común dez nominador de todas ellas es que ninguna es covacha, aunque en la 010 los clavos se localizan en la ante fosa de la covacha y la 004 en la fosa, sin tener relación con el individuo de la cámara. En línea con lo descrito anteriormente, no se puede hablar de la existencia sensu stricto de ataúdes, aunque alguno de los individuos se encontraba delimitado por una estructura trapezoidal de madera $^{71}$, que sin duda puede ser interpretada como tal, y así lo hemos hecho en otros casos similares ${ }^{72}$. No obstante, puede ser el momento de discutir la ausencia de fondo de madera en muchas de las tumbas con supuesto ataúd. Por un lado, se sigue admitiendo el uso de ataúdes ${ }^{73}$, pero el hecho de que no se conserve el fondo en la mayoría de los casos y sí el resto de las partes de esa cubrición, nos plantea una duda razonable que deberá ser resuelta conforme se avance en la investigación. Quizá, como se ha mencionado anteriormente, el entramado de madera pudo constituir un elemento de protección para el cadáver frente a la tierra que va a colmatar la fosa, permitiendo así, que el cuerpo no pierda el contacto con la tierra. $\mathrm{O}$ simplemente no se ha conservado por ser el lugar más expuesto a degradación.

Volviendo a las tumbas escalonadas, cuyo cierre subterráneo consiste en un tablazón de madera, éstas vienen siendo identificadas en yacimientos judíos a lo largo de la Península Ibérica como la ronda sur de Lucena, de época califal y post-califal (finales del siglo X y XI d.C.) ${ }^{74}$, y

\footnotetext{
${ }^{70}$ RuIZ TABOADA, La vida futura es para los devotos.

${ }^{71}$ En otros casos la estructura es rectangular, véase la tumba 005 (fig. 9) con 14 clavos repartidos simétricamente, relacionados con la tabla de cubierta.

${ }^{72}$ Ruiz TABOAdA, «La necrópolis medieval del Cerro de la Horca», pág. 31.

${ }^{73}$ Un ejemplo de ataúd completo -fondo incluido-, lo tenemos en la tumba 40 del IES Azarquiel; Ruz Taboada, La vida futura es para los devotos, pág. 67.

${ }^{74}$ Botella Ortega y Casanovas Miró, «El cementerio judío de Lucena (Córdoba)»; J. A. Riquelme Cantal y D. Botella Ortega, «La nécropole médiévale de Lucena:
} 


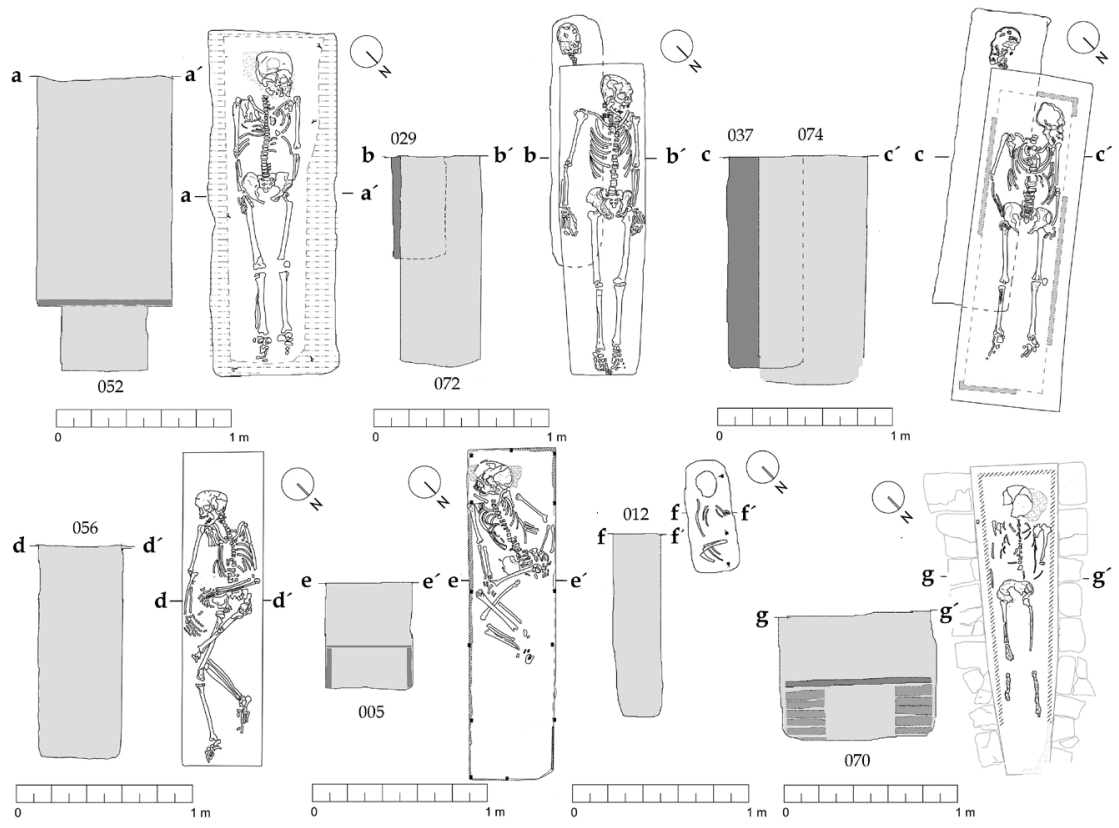

Figura 9: Diversos tipos de tumbas descritas en el texto relacionadas con el ritual de enterramiento judío.

más recientes como Ávila ${ }^{75}$, o Toledo, identificadas en la U2 del PERI de San Lázaro (Quixote Crea) ${ }^{76}$, General Villalba 20, $22^{77}$ o Valdivias Covarrubias $^{78}$, aunque en estas últimas no figuren adscritas a un ritual de enterramiento concreto.

Ya hemos mencionado que el común denominador de muchas de las fosas judías localizadas en el entorno del paleo-cauce es la destrucción de la fase andalusí de la necrópolis (fig. 9, T-072). No obstante, hay ejem-

contributions à l'archéologie juive en Séfarad», en L'Archéologie du judaïsme en France et en Europe, eds. P. Salmona y L. Sigal (Paris 2011) págs. 261-272: 265.

${ }^{75}$ B. Cabrera González, J. Caballero Arribas y J. Díaz de la Torre, «El cementerio judío medieval de ‘la Encarnación’ en Ávila», Sefarad 73:2 (2013) págs. 309-338: 323.

${ }^{76}$ Rodríguez Fernández y Rosado Tejerizo, «Excavación arqueológica».

${ }^{77}$ Rodríguez UnToria, «Excavación arqueológica».

${ }^{78}$ Requejo López y Maqueda García-Morales, «Excavaciones». 
plos en los que la destrucción se da también entre tumbas judías, como la T-074 cuya fosa altera una anterior, o la T-035 que no llega a destruir la más antigua (figs. 8 y 9). Esta destrucción es puntual y no es habitual su documentación en contextos judíos ${ }^{79}$. Las causas se pueden relacionar, como ocurrió con la reutilización del espacio funerario musulmán por parte judía, tanto con la pérdida de delimitación superficial de la tumba más antigua, como con el prolongado período de uso del área cementerial, lo que hace imposible su identificación previa a la excavación de la nueva fosa.

Con respecto a la posición de los cuerpos, la mayoritaria están en decúbito supino con brazos extendidos en cadera y algunas veces flexionados para que, al menos una de las manos, quede sobre la pelvis. Además, se han documentado diversos grados de flexión de piernas, común en este tipo de rituales ${ }^{80}$ cuya preparación y disposición difiere tanto en el fondo como en la forma, de los de la fase andalusí (fig. 9, T-005, T-012 y T-056). Hay constancia de sendos casos extremos de flexión en la parcela aneja a Villalba 25, en la U2 de San Lázaro (Quixote Crea) ${ }^{81}$, hasta el punto de que el cadáver debió requerir de una sujeción especial aunque, por desgracia, desconocemos su contextualización arqueológica.

Una gran mayoría de los cráneos descansa sobre almohadilla (002, 004, 005, 011, 018, 021, 032, 038, 039, 042, 043, 044, 050, 052, 055, 057, 061, 066 y 070). De nuevo, la escasez de datos empíricos obliga tan sólo a conjeturar sobre este tipo de reposaderos de cabeza. Llama la atención que ninguno de los individuos enterrados en covacha la usa, lo que debemos relacionarlo con la forma de deposición del cuerpo y su escasa colocación debido a la falta de espacio. También que en catorce de ellas se hayan documentado almohadillas, podría sugerir una posible asociación ataúd o armazón de madera y almohadilla.

${ }^{79}$ Cabe mencionar que en el sector centra del Cerro de la Horca se han llegado a documentar cambios extremos de alineación de tumbas en el empeño de respetar las preexistentes; RuIz TABOADA, «La necrópolis medieval del Cerro de la Horca», pág. 34.

${ }^{80}$ S. Fernández Esteban, «El cementerio judío de la ciudad de Segovia en el medievo», en Juderías y Sinagogas de la Sefarad medieval, eds. A. LóPEz Álvarez y R. IzQuierdo Benito (Cuenca 2003) págs. 557-583: 573.

${ }^{81}$ Rodríguez FernándeZ y Rosado TeJerizo, «Excavación arqueológica», pág. 231, figs. 9 y 11. 
La composición de esta almohadilla es frecuente objeto de discusión entre los investigadores. Ante la imposibilidad de disponer de sedimento de Tierra Santa, se solía recurrir a importar tierra de necrópolis cercanas que la tradición consideraba como especiales ${ }^{82}$. En el caso de Toledo, no sería de extrañar que fuera generadora de dicha tierra por su relevancia en Sefarad. Aún más difícil de identificar arqueológicamente es la relación del uso de la almohadilla con el mundo judeoconverso, en la necesidad de en el caso de ser enterrado con ataúd, no perder contacto con tierra virgen $^{83}$.

El análisis de los componentes de tres almohadillas documentadas en General Villalba 25 ha permitido establecer algunas consideraciones sobre el origen de la tierra que contenía. Los criterios de recogida han sido tanto el grosor como la pureza y color de sus componentes. Aunque dos de ellas eran cenizosas, su posterior lavado tamizado y examen determinó que se trataba de arena de grano fino medio posiblemente proveniente del arroyo identificado en los sondeos 1, 2 y 10 de la necrópolis (fig. 10, T-018 y T-074). Desconocemos el por qué de su aspecto cenizoso. La tercera, en cambio, es la más interesante pues presenta una composición granulométrica y de materiales revueltos similar a una cuarta muestra tonada de forma aleatoria en los niveles arenosos del arroyo. Mientras que en la muestra de la almohadilla (fig. 10, T-057), se han documentado esquirlas de hueso y cerámicas de diferente tipología -entre ellas un pequeño fragmento de sigillata-, la muestra del arroyo ha revelado parecida composición, con fragmentos cerámicos diversos y granulometría media gruesa (fig. 10). Esto permite establecer una relación directa entre la muestra del arroyo y la de una de las almohadillas lo que, sin duda, abre nuevas vías de investigación para este tipo de componentes.

En lo que respecta a los estudios antropológicos, sigue siendo una asignatura pendiente la elaboración de una tabla osteométrica de comparación que contemple este tipo de poblaciones. Las 51 tumbas de General Villalba son las primeras de Toledo en las que se ha podido realizar este

${ }^{82}$ CASAnovas Miró, «La arqueología funeraria judía», pág. 58.

${ }^{83}$ E. Cantera Montenegro, «Vida cotidiana de las aljamas judías en la corona de Aragón y Castilla», en Aragón-Sefarad (Zaragoza 2004) págs. 191-207: 201, y «Los últimos tiempos», pág. 77. 

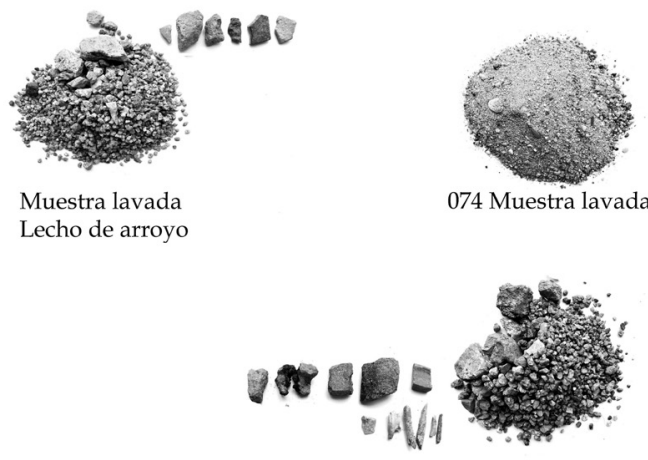

057 Muestra lavada

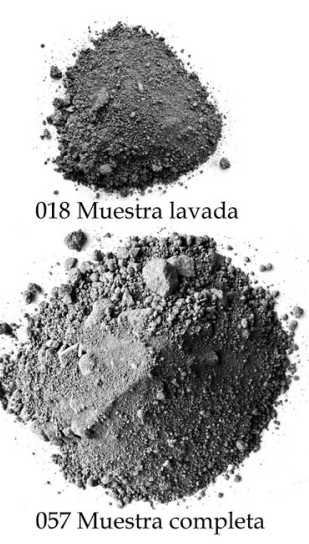

Figura 10: Muestras de tierra de las almohadillas pertenecientes a las tumbas 018, $057 \mathrm{y}$ 074 en relación con una muestra tomada en niveles arenosos del sondeo 1 (fig. 5).

tipo de estudios, siendo la muestra aún poco significativa estadísticamente (Tabla III). La morfometría nos interesa para conocer la adscripción tipológica y vinculación geográfica de estos individuos, para ello contamos como referencia los análisis de María y Antonio Prevosti realizados sobre la necrópolis judaica de Montjüich ${ }^{84}$, Ana Colet y otros en Tárrega ${ }^{85}$, Juan Pablo Diéguez Ramírez en Lucena ${ }^{86}$ o Calvo y Lerma sobre judíos de la aljama de Valencia ${ }^{87}$. En este último, se pone de manifiesto una semejanza con los tipos mediterráneos robustos o euroafricánidos, con una media de altura para individuos femeninos de 1,55 y masculinos de $1,70 \mathrm{~m}^{88}$. Espe-

${ }^{84}$ M. A. Prevosti y A. Prevosti «Restos humanos procedentes de una necrópolis judaica de Montjüich (Barcelona)», Trabajos del Instituto Bernardino de Sahagún de Antropología y Etnología XII (1951) págs. 65-148; A. Prevosti, «Estudio tipológico de los restos humanos hallados en la necrópolis judaica de Montjüich (Barcelona)», Sefarad 11:1 (1951) págs. 75-90: 75. Agradezco a Jordi Casanovas la información aportada a este respecto.

${ }^{85}$ Colet, Muntané, Ruiz, Saula y Subira de Galdácano, «Les fosses communes des Roquetes a Tárrega».

${ }^{86}$ J. P. DiéGuez Ramírez, Estudio bioantropológico comparado de tres necrópolis históricas excavadas en el Término municipal de Lucena (Córdoba). Tesis Doctoral, Universidad de Granada (2015).

${ }^{87}$ M. Calvo y J. V. Lerma, «Fossar dels Juheus», Saitabi 46 (1996) págs. 261-275.

${ }^{88}$ L. MANOUVRIER, «La détermination de la stature d'après les grands os des Membres», Mém. Soc. Anthrop. Paris 4 (1893) págs. 347-402; M. TrotTer, «Estimation of stature from intact long limb bones», Personal Identification in Mass Disasters 71 (1970) pág. 83. 
EL LÍMITE SUR DE LA NECRÓPOLIS MEDIEVAL JUDÍA DEL CERRO DE LA HORCA (TOLEDO) 153

remos que en un futuro la investigación avance y podamos saber algo más del desarrollo de estos grupos.

Lo que sí desvelan los estudios antropológicos es que el empleo de sudario debió ser común en las tres religiones. Pese a que no suelen dejar resto material, la posición anatómica de los cuerpos puede dar fe de su uso ${ }^{89}$.

\begin{tabular}{|c|c|c|c|c|c|}
\hline Tumba & Edad & Sexo & Estatura $(\mathrm{cms})$ & Posición & Observaciones \\
\hline $\mathrm{T}-001$ & $24-30$ & $\mathrm{~F}$ & 155 & Decúbito supino & \\
\hline $\mathrm{T}-002$ & $30-35$ & M & $170-175$ & Decúbito supino & Entesopatías, caries \\
\hline T-004 & $24-30$ & M & $165-170$ & Decúbito supino & Artrosis, caries \\
\hline T-005 & $12-14$ & Indet. & $130-140$ & $\begin{array}{l}\text { Dec. Supino, } \\
\text { hiperflexión }\end{array}$ & Hipoplasia \\
\hline T-009 & Indet. & & & Decúbito supino & \\
\hline $\mathrm{T}-010$ & $20-24$ & M & $175-180$ & Decúbito supino & Hipoplasia \\
\hline $\mathrm{T}-011$ & $18-22$ & M & 165 & Decúbito supino & Reabsorción alveolar \\
\hline T-012 & $1-3$ & Indet. & 55 & $\begin{array}{c}\text { Dec. supino, } \\
\text { piernas flexionadas }\end{array}$ & \\
\hline $\mathrm{T}-014$ & $20-24$ & M & 175 & Decúbito supino & \\
\hline $\mathrm{T}-015$ & $20-24$ & $\mathrm{~F}$ & $165-170$ & Decúbito supino & Entesopatía \\
\hline $\mathrm{T}-017$ & Ad. Indet. & $\mathrm{F}$ ? & 160 & Decúbito supino & \\
\hline T-018 & $30-35$ & $\mathrm{~F}$ & $160-165$ & Decúbito supino & Caries \\
\hline T-019 & $2-4$ & & 91 & Decúbito supino & \\
\hline $\mathrm{T}-020$ & $30-35$ & $\mathrm{~F}$ & $155-160$ & Decúbito supino & Caries \\
\hline $\mathrm{T}-021$ & $40-50$ & Indet. & Indet. & Decúbito supino & \\
\hline $\mathrm{T}-023$ & $4-6$ & & 112 & Decúbito supino & \\
\hline $\mathrm{T}-025$ & $30-35$ & M & $160-165$ & Decúbito supino & Osteofitosis \\
\hline T-026 & $24-30$ & M & 170 & $\begin{array}{l}\text { Dec. Lateral } \\
\text { izquierdo ¿? }\end{array}$ & \\
\hline $\mathrm{T}-030$ & $30-35$ & M? & $165-170$ & Decúbito supino & Hipoplasia \\
\hline $\mathrm{T}-031$ & $20-24$ & $\mathrm{~F}$ & 160 & Decúbito supino & \\
\hline Т.032 & $20-24$ & M & Indet. & Decúbito supino & \\
\hline $\mathrm{T}-034$ & $0,5-1,5$ & Indet. & 64 & Indeterminado & \\
\hline $\mathrm{T}-035$ & Indet. & $\mathrm{F}$ & 150 & Decúbito supino & \\
\hline
\end{tabular}

\footnotetext{
${ }^{89}$ Ruiz TABoada, La vida futura es para los devotos, pág. 103.
} 
Núm

Tumba Edad Sexo Estatura $(\mathrm{cms})$

Posición Observaciones

\begin{tabular}{|c|c|c|c|c|c|}
\hline T-036 & $20-24$ & M & $160-165$ & Decúbito supino & \\
\hline T-037 & $18-22$ & M & Indet. & Indeterminado & \\
\hline $\mathrm{T}-038$ & $30-35$ & $\mathrm{~F}$ & 160 & Decúbito supino & Caries \\
\hline T-039 & $18-22$ & Indet. & Indet. & Decúbito supino & \\
\hline $\mathrm{T}-042$ & $18-22$ & M & $170-175$ & Decúbito supino & \\
\hline $\mathrm{T}-043$ & $40-50$ & M & Indet. & Decúbito supino & Artrosis \\
\hline $\mathrm{T}-044$ & $24-30$ & M & $170-175$ & Decúbito supino & Reabsorción alveolo \\
\hline $\mathrm{T}-045$ & $4-6$ & Indet. & Indet. & Decúbito supino & \\
\hline T-046 & $18-22$ & $\mathrm{~F}$ & $160-165$ & Decúbito supino & \\
\hline $\mathrm{T}-048$ & $24-30$ & $\mathrm{~F}$ & 160 & Decúbito supino & Caries, reabsorción alv. \\
\hline $\mathrm{T}-050$ & $30-35$ & $\mathrm{~F}$ & $160-165$ & Decúbito supino & Caries, gingivitis, reabs. \\
\hline $\mathrm{T}-051$ & Indet & $\mathrm{F}$ & Indet. & Decúbito supino & Osteofitosis lumbar \\
\hline $\mathrm{T}-052$ & $35-40$ & M & $170-175$ & Decúbito supino & Caries \\
\hline $\mathrm{T}-053$ & $20-24$ & $\mathrm{~F}$ & 160 & Decúbito supino & \\
\hline $\mathrm{T}-054$ & $5-9$ & Indet. & 110 & Decúbito supino & \\
\hline $\mathrm{T}-055$ & 24-30 & M & 175 & Decúbito supino & Sarro \\
\hline $\mathrm{T}-056$ & $18-22$ & $\mathrm{~F}$ & $160-165$ & $\begin{array}{c}\text { Semi dec. lat. } \\
\text { derecho, piernas } \\
\text { semi flexionadas }\end{array}$ & Hiperplatimería tibias \\
\hline $\mathrm{T}-057$ & $30-35$ & $\mathrm{~F}$ & 165 & Decúbito supino & \\
\hline $\mathrm{T}-059$ & $7-11$ & Indet. & $120-124$ & Indeterminada & \\
\hline $\mathrm{T}-060$ & Juvenil & Indet. & Indet. & Indeterminada & \\
\hline $\mathrm{T}-061$ & 24-30 & $\mathrm{F}$ & 165 & Decúbito supino & \\
\hline T-066 & $18-22$ & Indet. & Indet. & Decúbito supino & \\
\hline $\mathrm{T}-067$ & Niño indet. & & & Decúbito supino & \\
\hline $\mathrm{T}-070$ & $24-30$ & M & Indet. & Decúbito supino & \\
\hline $\mathrm{T}-072$ & Indet. & Indet. & 175 & Decúbito supino & \\
\hline $\mathrm{T}-073$ & $35-40$ & $\mathrm{~F}$ & 15 & Decúbito supino & Entesopatía \\
\hline T-074 & Indet. & M & 165 & Decúbito supino & Caries \\
\hline T-075 & Fosa vacía & & & & \\
\hline
\end{tabular}

Tabla III: Estudio Antropológico de las tumbas de adscripción judía (Realizado por Isabel Molero Rodrigo).

M.: masculino, F.: femenino, Indet.: indeterminado, n/neo.: neonato. 


\section{CONSIDERACIONES FINALES}

En los últimos años hemos asistido al auge de la investigación funeraria judía medieval en España. De los artículos pioneros sobre el descubrimiento e inventario de inscripciones o enterramientos judíos publicados en la revista Sefarad desde $1943^{90}$, se ha pasado a la organización de foros científicos y a la edición de trabajos monográficos que describen la problemática y caracterización de este mundo tanto a nivel nacional como internacional. Prueba de ello son las reuniones organizadas por el Museo de Historia de Barcelona en el año 2009 sobre intervenciones arqueológicas en necrópolis históricas ${ }^{91}$, o por el Instituto Nacional de Investigaciones Arqueológicas Preventivas en París en 2010 sobre Arqueología del Judaísmo en Francia y en Europa ${ }^{92}$. Además, la excavación sistemática de necrópolis como Tárrega ${ }^{93}$, Lucena $^{94}$, Sevilla $^{95}$, Ávila ${ }^{96}$ o Valladolid ${ }^{97}$, está permitiendo ampliar la información tanto de la tipología de las tumbas, contexto funerario y cronología, como del patrón de enterramiento que se infiere del estudio arqueológico de los restos. La caracterización arqueológica de estos cementerios, con todas las reservas que la aplicación del método pueda generar a la hora de interpretar ritos y costumbres del pasado, permite contrarrestar tanto la escasez de materiales asociados con

${ }^{90}$ F. Cantera Burgos, «Lápidas hebraicas del museo de Toledo», Sefarad 3:1 (1943) págs. 107-114.

${ }^{91} \mathrm{~L}$. COLOMER, La intervención arqueológica en las necrópolis históricas: los cementerios judios (Barcelona 2012).

${ }^{2}$ P. Salmona, L. Sigal (eds.), L'Archéologie du judaïsme en France et en Europe (Paris 2011).

${ }^{93}$ Colet, Muntané, Ruiz, Saula y Subira de Galdácano, «Les fosses communes des Roquetes a Tárrega».

${ }^{94}$ D. Botella Ortega y J. Casanovas Miró, «El cementerio judío de Lucena (Córdoba)», MEAH. Sección Hebreo 58 (2009) págs. 3-25.

${ }^{95}$ I. Santana Falcón y A. Mantero Tocino, «La muerte en la aljama judía de Sevilla», en De la muerte en Sefarad. La excavación arqueológica en la nueva sede de la Diputación de Sevilla (1995) págs. 81-118.

${ }^{96}$ Cabrera González, Caballero Arribas y Díaz de la Torre, «El cementerio judío medieval de 'la Encarnación' en Ávila».

${ }^{97}$ J. Moreda Blanco y R. Serrano Noriega, La necrópolis judía del Paseo de la Acera de Recoletos (Valladolid) (=Arqueología en Castilla y León 18 [Valladolid 2009]). 
la cultura judía, como la ausencia de lápidas con inscripciones hebreas en contexto funerario que, sin duda, facilitaría su análisis.

En Toledo, el descubrimiento del cementerio judío en el año 2009 marca un antes y un después en el conocimiento del mundo funerario medieval de la ciudad. Hasta ese momento, no había una caracterización clara para los diferentes rituales de enterramiento de las tres religiones que coexistieron en Toledo durante la Edad Media. Por norma, la tendencia era aplicar genéricamente el término mudéjar para definir aquellas tumbas que no cuadraban con la descripción oficial. En los últimos años se ha podido invertir dicha tendencia y ahora se empieza no sólo a contextualizar arqueológicamente los rituales de enterramiento de las tres religiones, sino a comprender la dinámica de desarrollo y cambio en sus respectivas necrópolis, y su relación con otros espacios cementeriales colindantes. La excavación en el año 2014 de un pequeño solar en el límite sur del Cerro de la Horca, en la actual calle General Villalba 25, nos ha permitido ampliar la información sobre la posible ocupación y expansión del cementerio judío y su relación con otros cercanos.

De este estudio se deriva que en el límite sur del cementerio del Cerro de la Horca confluyen tres lugares de enterramiento distintos: el judío homónimo, el musulmán del camino de Madrid y, posiblemente, el cristiano de la ermita de San Eugenio. Los enterramientos interpretados como judíos siguen el mismo patrón al ya documentado en el sector central de su necrópolis en cuanto a profundidad de las fosas y colocación del cadáver. Además, se han conseguido individualizar en contexto arqueológico dos nuevos tipos de tumba que se suman a la completa muestra existente para este ritual de enterramiento ${ }^{98}$ : covacha lateral y escalonada con cierre de madera.

Comprender la dinámica de contactos entre cementerios resulta fundamental a la hora de identificar arqueológicamente estos rituales de enterramiento. El caso del límite sur del cementerio del Cerro de la Horca ilustra esta problemática, donde la ausencia de barreras físicas dificulta la correcta interpretación y sistematización del registro material. De esta forma, el método aplicado podría ser extrapolado a cualquier zona de contacto con similar grado de contaminación a ámbito local o nacional.

\footnotetext{
${ }^{98}$ RuIZ TABOADA, «La necropole juive de Tolède».
} 
Aún quedan por definir el resto de límites de este cementerio entre los que, sin duda, el suroeste (entorno del actual IES María Pacheco, fig. 2, núm. 1) debe contar con una problemática similar, por ser contacto con la llanura norte de Toledo, igualmente saturada de necrópolis. Por el contrario, el límite norte sería el menos expuesto a contaminación por su lejanía del núcleo urbano.

Como hemos visto, resulta especialmente complicado establecer diferencias arqueológicas entre rituales de enterramiento. En el caso judío, la ausencia de restos epigráficos o ajuares en las tumbas dificulta establecer una adscripción concreta, lo que hace que estos enterramientos puedan no diferir mucho de otras tradiciones religiosas.

Aunque no existe mucha información escrita sobre el enterramiento judío histórico, algunos preceptos de la Biblia en esa materia como la existencia de tumbas familiares (Gen 23), la preferencia por ser enterrado junto a algún ancestro o familiar (Gen 49:29), la ausencia de cremaciones (Jer 34:5) o el uso o no de ataúdes según los casos (2 Sam. 3:31; Gen 50:26), pueden encontrar reflejo en el registro arqueológico, con las reservas que su interpretación conlleva. De momento, nos conformamos con avanzar en el conocimiento arqueológico de un ritual, claramente diferenciado de las otras dos religiones mayoritarias presentes en el Toledo de la Edad Media, al tiempo que esperamos nuevos hallazgos que confirmen o maticen muchas de las hipótesis desarrolladas en este artículo.

Recibido: 26/02/2016

Aceptado: 06/05/2016 